\title{
Prolactin Rescues Immature B Cells from Apoptosis-Induced BCR-Aggregation through STAT3, Bcl2a1a, Bcl212, and Birc5 in Lupus-Prone MRL/lpr Mice
}

\author{
Rocio Flores-Fernández ${ }^{1}$, Angélica Aponte-López 2,3 ${ }^{\mathbb{D}}$, Mayra C. Suárez-Arriaga ${ }^{2,4}$, Patricia Gorocica-Rosete 5 , \\ Alberto Pizaña-Venegas ${ }^{6}$, Luis Chávez-Sanchéz ${ }^{1}$, Francico Blanco-Favela ${ }^{1}$, Ezequiel M. Fuentes-Pananá ${ }^{2, *(D)}$ \\ and Adriana K. Chávez-Rueda ${ }^{1, *,+}$
}

Citation: Flores-Fernández, R.; Aponte-López, A.; Suárez-Arriaga, M.C.; Gorocica-Rosete, P.;

Pizaña-Venegas, A.; Chávez-Sanchéz, L.; Blanco-Favela, F.; Fuentes-Pananá, E.M.; Chávez-Rueda, A.K. Prolactin Rescues Immature B Cells from Apoptosis-Induced BCR-Aggregation through STAT3, Bcl2a1a, Bcl212, and Birc5 in Lupus-Prone MRL/lpr Mice. Cells 2021, 10, 316. https://doi.org/ 10.3390/cells10020316

Academic Editor: Yasmina Juarranz Received: 28 November 2020

Accepted: 24 January 2021

Published: 4 February 2021

Publisher's Note: MDPI stays neutral with regard to jurisdictional claims in published maps and institutional affiliations.

Copyright: (C) 2021 by the authors Licensee MDPI, Basel, Switzerland. This article is an open access article distributed under the terms and conditions of the Creative Commons Attribution (CC BY) license (https:// creativecommons.org/licenses/by/ $4.0 /)$.
1 UIM en Inmunologia, Hospital de Pediatría, CMN SIGLO XXI, Instituto Mexicano del Seguro Social, Mexico City 06720, Mexico; chio_tom@hotmail.com (R.F.-F.); luis_chz@hotmail.com (L.C.-S.); fblanco5@hotmail.com (F.B.-F.)

2 Unidad de Investigación en Virología y Cáncer, Hospital Infantil de Mexico Federico Gómez, Mexico City 06720, Mexico; angibel06@hotmail.com (A.A.-L.); mostancmayra@hotmail.com (M.C.S.-A.)

3 Programa de Doctorado en Ciencias Biomédicas, Universidad Nacional Autónoma de Mexico, Mexico City 04510, Mexico

4 Laboratorio de Biotecnología y Bioinformática Genómica, ENCB, Instituto Politécnico Nacional, Mexico City 11340, Mexico

5 Departamento de Investigación en Bioquímica, Instituto Nacional de Enfermedades Respiratorias "Ismael Cosió Villegas", Mexico City 14080, Mexico; gorocicap@gmail.com

6 Unidad de Investigación y Bioterio, Instituto Nacional de Enfermedades Respiratorias "Ismael Cosió Villegas", Mexico City 14080, Mexico; apv38@hotmail.com

* Correspondence: empanana@yahoo.com or Ezequiel.Fuentes@alumni.bcm.edu (E.M.F.-P.); akarina_chavez@facmed.unam.mx or akarina_chavez@yahoo.com.mx (A.K.C.-R.); Tel.: +52-5544349663 (E.M.F.-P.); +52-555627694 (A.K.C.-R.)

+ Lead contact.

Abstract: Self-reactive immature B cells are eliminated through apoptosis by tolerance mechanisms, failing to eliminate these cells results in autoimmune diseases. Prolactin is known to rescue immature $B$ cells from B cell receptor engagement-induced apoptosis in lupus-prone mice. The objective of this study was to characterize in vitro prolactin signaling in immature B cells, using sorting, PCR array, RTPCR, flow cytometry, and chromatin immunoprecipitation. We found that all B cell maturation stages in bone marrow express the prolactin receptor long isoform, in both wild-type and MRL/lpr mice, but its expression increased only in the immature B cells of the latter, particularly at the onset of lupus. In these cells, activation of the prolactin receptor promoted STAT3 phosphorylation and upregulation of the antiapoptotic Bcl2a1a, Bcl212, and Birc5 genes. STAT3 binding to the promoter region of these genes was confirmed through chromatin immunoprecipitation. Furthermore, inhibitors of prolactin signaling and STAT3 activation abolished the prolactin rescue of self-engaged MRL/lpr immature B cells. These results support a mechanism in which prolactin participates in the emergence of lupus through the rescue of self-reactive immature B cell clones from central tolerance clonal deletion through the activation of STAT3 and transcriptional regulation of a complex network of genes related to apoptosis resistance.

Keywords: prolactin receptor; prolactin; immature B cells; STAT3; Birc5; Bcl2a1a; systemic lupus erythematosus; MRL/lpr mice

\section{Introduction}

$B$ cell ontogeny starts in the bone marrow (BM) and occurs through several sequential stages, from pro-B and pre-B to immature B cells. Immature B cells are the first ones expressing surface IgM, exiting the BM to complete maturation in secondary lymph organs [1]. During B cell development, there are several checkpoints that remove self-reactive 
clones through tolerance mechanisms (receptor editing, clonal deletion, and anergy). In the $\mathrm{BM}$, central tolerance is conducted in immature B cells, removing approximately $85 \%$ of them [2,3]. Defects in these tolerance processes have been implicated in the pathogenesis of autoimmune diseases such as systemic lupus erythematosus (SLE) [4].

SLE is a chronic systemic autoimmune disease with an abnormal interplay between innate and adaptive immunity, breach of immune tolerance, production of autoantibodies, and immune complex deposition with multiple organ damage. SLE is considered a multifactorial disease in which immunological, genetic, epigenetic, environmental, and hormonal aspects play an important role in its development. SLE typically affects young women at reproductive age (with a female:male ratio of 9:1); the female predominance has been attributed to the immunostimulatory properties of hormones such as prolactin (PRL) $[5,6]$. Hyperprolactinemia has been reported in $15-33 \%$ of patients with lupus, and PRL levels have shown a direct correlation with the clinical and serological disease activity [7-9]. We have previously shown that high levels of PRL exacerbate the disease in a murine experimental model of SLE-like disease; we observed an increase in anti-dsDNA antibodies, autoantibody deposition, and damage to kidneys, which was evidenced through pathogenic proteinuria levels. We observed the expression of the PRL-receptor (extracellular domain) in all maturation stages of B cells, both in control mice (C57BL/6) and mice that developed SLE (MRL and MRL/lpr). However, the level of receptor expression through the $B$ cell maturation stages was different between the control and disease models $[10,11]$. Furthermore, we found that PRL can rescue immature B cells from apoptosis after BCR (B cell receptor) cross-linking in the MRL/lpr strain and in the WEHI-231 cell line [12].

Different isoforms of the PRL receptor carry identical extracellular but different intracellular domains, which determine the activation of different signaling transduction pathways. One long and three short isoforms have been reported in mice. PRL binding to the long isoform results in a wide range of activation of numerous kinases, including JAK2, STAT, MAPK, PI3K, and AKT [13,14]. In contrast, the short isoforms suppress signaling through the JAK2-STAT pathway due to heterodimer formation with the long isoform [15]. The short isoforms also exhibit long isoform-independent activities upon PRL engagement [16]. Thus, the activated pathway and the resulting PRL effector functions depend on the isoform and cell type in which the PRL-receptor is engaged $[15,17,18]$. For instance, PRL promotes the proliferation, differentiation, and survival of mammary glands through JAK-STAT5 and PI3K-AKT signaling [19], while it activates STAT1 and STAT5 in endometrial cells [20].

In this study, we determined the isoform of the receptor expressed on immature $B$ cells of wild-type and lupus-prone MRL/lpr mice, and the signaling pathways activated upon PRL receptor engagement to understand the mechanism through which PRL rescues autoimmune cells from apoptosis-induced clonal deletion. We found that BM-maturing B cells expressed only the PRL receptor long isoform. When immature B cells were activated with PRL, it induced the activation of STAT3, which transcriptionally regulated the expression of apoptosis-related genes, mainly Bcl2l2, Bcl2a1a, Birc5, Gadd 45a, and Casp8, thus rescuing immature $B$ cells from apoptosis.

\section{Materials and Methods}

\subsection{Cell Line}

The WEHI-231 murine B lymphoma cell line (ATCC, Manassas, VA, USA) [21] was maintained in RPMI 1640 medium (Hyclone, Logan, UT, USA) supplemented with 10\% heat-inactivated fetal bovine serum (FBS, Hyclone), $1 \%$ penicillin and streptomycin (Invitrogen, Carlsbad, CA, USA), $1 \%$ sodium pyruvate (Hyclone), and $0.1 \% \beta$-mercaptoethanol (Invitrogen, Carlsbad, CA, USA) at $37^{\circ} \mathrm{C}$ under $5 \% \mathrm{CO}_{2}$.

\subsection{Mice}

Mouse strains were bred in the specific pathogen-free animal facility of the Instituto Nacional de Enfermedades Respiratorias "Ismael Cosio Villegas". All studies were approved 
by the Animal Care Committee of the Instituto Nacional de Enfermedades Respiratorias "Ismael Cosio Villegas" and the Hospital de Pediatria, Centro Medico Nacional Siglo XXI, IMSS (protocol number R-2017-785-114); 9-15-week-old mice were used for all experiments, which were performed in accordance with approved guidelines established in Mexico (NOM-062-ZOO-1999) and by the NIH Guide for the Care and Use of Laboratory Animals. MRL/MpJFASlpr (MRL/lpr) mice were purchased from Jackson Laboratory (Bar Harbor, ME, USA) and C57BL/ 6 mice were purchased from Harlan (Indianapolis, IN, USA).

\subsection{Prolactin Hormone and Inhibitors}

We used murine recombinant PRL (National Hormone and Peptide Program, NIH). PRL receptor activation was ablated with an inhibitor (PRL-inh, G129R), a recombinant analog of the PRL with a single amino acid substitution to create an antagonist of the PRL receptor, which was donated by the manufacturer (Oncolix, Houston, Tex, USA) [22]. Stattic (Cell Signaling Technology, Danvers, MA, USA) is a nonpeptidic selective STAT3 inhibitor. This small molecule prevents the binding of tyrosine-phosphorylated peptide motifs to the STAT3 SH2 domain [23].

\subsection{Antibodies}

The following antibodies were used: anti-B220 MicroBeads (clone RA3-6B2), PEconjugated anti-B220 (clone RA3-6B2), PE-Cy7-conjugated anti-CD23 (clone B3B4), APCconjugated anti-IgM (clone 11/41), PE-conjugated anti-AKT (clone REA677), PE-conjugated anti-ERK1/2 (clone REA152); all these were from Miltenyi Biotec (Bergisch Gladbach, Germany). We also used FITC-conjugated anti-CD43 (clone eBioR2/60) and VioBlueconjugated anti-STAT5 (clone SRBCZX) from eBioscience (San Diego, Cal, USA); PEconjugated anti-STAT1 (clone 1A5158B) and PE-conjugated anti-STAT3 (clone 13A3-1) from BioLegend (San Diego, Cal, USA); anti-IgM F( $\left.\mathrm{ab}^{\prime}\right) 2$ antibody (polyclonal), Jackson Immunoresearch (West Grove, PA, USA); and phospho-Stat3 (Tyr705) rabbit IgG antibody (\#9131) and normal rabbit IgG (\#2729) from Cell Signaling Technology Company.

\subsection{Purification of B Cells (B220+CD23-) from the Bone Marrow}

Nine-week-old mice were euthanized, and BM cells were collected through flushing the femoral shafts with cold RPMI supplemented with $2 \%$ FBS and 2 mM EDTA (IBI Scientific, Dubuque, IA, USA). Red blood cells were depleted with a lysis buffer (Sigma-Aldrich, St. Louis, MO, USA) and incubated with anti-CD23 MicroBeads; mature recirculating $B$ cells were removed with the magnetically activated cell-sorting (MACS) system (Miltenyi Biotec) through positive selection using LS columns (Miltenyi Biotec). The negative fraction was recovered and subsequently incubated with anti-B220 MicroBeads (Miltenyi Biotec), so that B220+CD23- BM cells were purified by positive selection.

\subsection{Analysis of the Signaling Pathways}

WEHI-231 cells and B220+CD23- cells from the BM (9-week-old mice) were incubated for $30 \mathrm{~min}$ in basal media alone or with the following signaling pathway inhibitors $(10 \mu \mathrm{M})$ : G129R to inhibit the PRL receptor, GSK690693 to inhibit PI3K (Sigma-Aldrich), and Stattic to inhibit STAT3. Subsequently, cells were incubated with PRL (50 ng/mL) for $30 \mathrm{~min}$ and fixed with $1 \times$ BD Phosflow Lyse/FIx Buffer $5 \times$ (BD Biosciences, San Jose, Cal, USA) for 10 min. Cells were permeabilized with Perm Buffer III from BD Phosflow (BD Biosciences) to determine STAT3 phosphorylation and activity in apoptosis rescue assays, and with IC Fixation Buffer (eBioscience) to determine AKT and ERK $1 / 2$ phosphorylation at $4{ }^{\circ} \mathrm{C}$ for $30 \mathrm{~min}$. Cells were washed with FACS buffer or with Permawash and incubated at $4{ }^{\circ} \mathrm{C}$ for 30 min with the antibodies for flow cytometry analysis. Data were acquired using a MACSQuant Analyzer 10 cytometer (Miltenyi Biotec) and analyzed with FlowJo software (Tree Star, Ashland, OR, USA). 


\subsection{Sorting $B$ Cells from $B M$}

Single-cell suspensions of B220+ B cells from BM were incubated with fluorescently labeled antibodies specific for CD43, B220, IgM, and CD23 in a staining buffer (PBS with $0.5 \% \mathrm{BSA}$ ) for $20 \mathrm{~min}$ at $4{ }^{\circ} \mathrm{C}$. Further, the cells were incubated with DAPI to select living cells (DAPI-) and washed, then pro-B (B220+CD23-CD43+IgM-), pre-B (B220+CD23CD43-IgM-), and immature B cells (B220+CD23-CD43-IgM+) were isolated [11]. Cell sorting was performed using a FACS Influx Sorter (BD Biosciences). The purity of sorted cells ranged from $95 \%$ to $98 \%$.

\subsection{RT-PCR for PRL-Receptor Isoforms}

To determine the expression of PRL receptor isoforms, real-time PCR was performed using primers synthesized by Integrated DNA Technologies (IDT, Coralville, IA USA): for B-actin (housekeeping control): 5'-GAGGAGGCTCTGGTTCAACA-3' (left) and 5' CAGTAAATGCCACGAACGAA-3' (right). To determine the PRL receptor isoforms, 3 primers were used: common $5^{\prime}$-AAGCCAGACCATGGATACTGGAG-3' (left), long isoform $5^{\prime}$-AGCAGTTCTTCAGACTTGCCCTT-3' (right), and short isoform 5'-TTGTATTTGCTTGC AGAGCCAGT-3' (right). The samples were run in the LightCycler II thermal cycler (Roche, Germany) under the following conditions: 1 cycle of $95^{\circ} \mathrm{C}$ for $15 \mathrm{~min} ; 40$ cycles of $95^{\circ} \mathrm{C}$ for $10 \mathrm{~s}, 61^{\circ} \mathrm{C}$ for $30 \mathrm{~s}$, and $72{ }^{\circ} \mathrm{C}$ for $30 \mathrm{~s}$; and 1 cycle of $72{ }^{\circ} \mathrm{C}$ for $30 \mathrm{~s}$. The relative expression was analyzed using the $2^{-\Delta \Delta \mathrm{Ct}}$ formula. The murine breast cancer cell line EpH4 1424 was used as a positive control for expression of the long and short PRL-receptor isoforms.

\subsection{PCR Array and RT-PCR}

The expression of 84 genes related to apoptosis was evaluated in immature B cells from both C57BL/ 6 and MRL/lpr mice using the Mouse Apoptosis RT2 Profiler PCR Array (PAMM-012Z, Qiagen, The Netherlands) in a 96-well plate format compatible with the LightCycler 96 thermocycler. Sample processing was performed according to the manufacturer's instructions using $\mathrm{RT}^{2}$ SYBR Green qPCR Mastermix (Qiagen, Spoorstraat KJ Venlo, Netherlands ). The results were analyzed with the Gene Globe Data Analysis Center (Qiagen), which normalized all gene expression data and generated the relative expression value. The expression of some genes was confirmed through RT-PCR using the LightCycler 96 thermocycler. The primers used were synthesized by Integrated DNA Technologies (IDT) and were BCL2L1 5'-GGACCGCGTATCAGAG-3' (left) and 5'GCATTGTTCCCGTAGAG-3' (right), and BIRC5 5' -CCCGATGACAACCCGATA-3' (left) and $5^{\prime}$-CATCTGCTTCTTGACAGTGAGG- $3^{\prime}$ (right). The PCR conditions were as follows: 1 cycle of $95^{\circ} \mathrm{C}$ for $15 \mathrm{~min} ; 40$ cycles of $95^{\circ} \mathrm{C}$ for $10 \mathrm{~s}, 61^{\circ} \mathrm{C}$ for $30 \mathrm{~s}$, and $72{ }^{\circ} \mathrm{C}$ for $30 \mathrm{~s}$; and 1 cycle of $72{ }^{\circ} \mathrm{C}$ for $30 \mathrm{~s}$. The relative expression was analyzed using the $2^{-\Delta \Delta \mathrm{Ct}}$ formula.

\subsection{Analysis of Gene Expression}

The transcriptional profile of 84 genes related to apoptosis in immature B cells from 9-week-old mice was analyzed under the following conditions: non-stimulated (control), stimulated with PRL alone, or previously treated with the inhibitors G129R and Stattic, as described in the analysis of signaling pathways. One experiment was performed for each experimental condition. To identify the optimal normalization for gene expression among the set of housekeeping genes included in the array, NormFinder V20 software (Aarhus University, Aarhus, Denmark was used [24]. GAPDH was found to be the most stable gene under all experimental conditions (Table S1), and thus gene expression was calculated relative to this housekeeping gene using the $2^{-\Delta \Delta C t}$ method (Table S1).

After normalization, data analysis was performed in the Gene Globe Data Analysis Center web portal (Qiagen). We first assessed the PRL-altered genes in C57BL/6 and MRL/lpr cells independently, using their respective unstimulated conditions as reference values. Genes with fold change values higher than 2.5 over unstimulated cells were considered to be significantly altered. We then compared the PRL-altered genes in both MRL/lpr and C57BL/ 6 immature B cells. For this, a nonsupervised hierarchical clustergram 
and a heat map of gene expression were constructed. We also evaluated the specific genes altered by PRL in MRL/lpr immature B cells by comparing PRL conditions against the inhibitors in a nonsupervised hierarchical clustergram and a heat map of gene expression. To confirm the genes altered directly by PRL stimulation, we performed a supervised analysis, using the unstimulated and the inhibitors cells as control groups. Altered genes shared by different conditions were visualized using Venn diagrams in the Bioinformatics and Evolutionary Genomics portal.

\subsection{Enrichment of Transcription Factors and Biological Processes}

To infer transcription factors related to the differentially expressed genes after PRL stimulation of immature B cells, we used the ChEA3-Chip-X Enrichment Analysis Version 3 (https: / / amp.pharm.mssm.edu/chea3/). As input, we used the list of upregulated and downregulated genes observed after the analysis of PRL vs. the control and inhibitors in the MRL/lpr immature-B cells, and upregulated and downregulated genes were analyzed independently. The transcription factors with the most significant scores were chosen, and we created a new list that included transcription factors and the upregulated and downregulated genes to build a protein-protein interaction network using STRING v1.4.2 implemented (https://apps.cytoscape.org/apps/stringapp) in Cytoscape v3.6.1 (https://apps.cytoscape.org). The protein-protein interaction network was determined using an interaction score of 0.4 , and each interaction was defined by neighborhood, gene fusion, co-occurrence, co-expression, experimental evidence, databases, and text mining. A functional enrichment analysis was conducted using STRING enrichment in STRING v1.4.2 in Cytoscape v3.6.1. The results were represented in the protein-protein interaction network through a donut chart, where each process was represented by a different color. Additionally, we determined the centrality measures closeness and betweenness centrality in Cytoscape. Each parameter was represented in the protein-protein interaction network. The same workflow was utilized to analyze the upregulated and downregulated genes.

\subsection{Chromatin Immunoprecipitation Assays}

WEHI-231 cells and immature B cells from 9-week-old C57BL/6 and MRL/lpr mice were incubated with PRL for $1 \mathrm{~h}$. The EpiTect ChIP OneDay Kit (Qiagen) protocol was used, which includes an antibody anti-RNA Polymerase II as a positive control. A rabbit IgG isotype antibody was used as negative isotype control for the immunoprecipitation. For immunoprecipitation, the anti-IgG and anti-pSTAT3 antibodies were used (Cell Signaling Technology). We also included a nontemplate control in the PCR reaction (Table S2). The following formula was used to determine the fold enrichment:

$$
\Delta \mathrm{CT}(\text { normalized IP) }=\mathrm{Cp}(\mathrm{IP})-\mathrm{Cp}(\mathrm{IgG})
$$

Fold Enrichement $=2[-\Delta \mathrm{CT}($ normalized IP $)]$

\subsection{Apoptosis Assays}

WEHI-231 cells and immature B cells from 9-week-old mice were preincubated for 30 min with G129R (PRL-inh), GSK, or Stattic and incubated with PRL for $1 \mathrm{~h}$ before stimulating them with anti-IgM F $(\mathrm{ab}) 2(10 \mu \mathrm{g} / \mathrm{mL})$ to induce clonal deletion or apoptosis for $48 \mathrm{~h}$ (WEHI-231) or $18 \mathrm{~h}$ (murine B cells). Cells were washed with PBS and incubated with Ghost-Red (Tonbo Biosciences, San Diego, CA, USA) at $4{ }^{\circ} \mathrm{C}$ for $30 \mathrm{~min}$. For caspase- 3 staining, the cells were permeabilized with Cytofix or Cytoperm (BD Biosciences) at $4{ }^{\circ} \mathrm{C}$ for $1 \mathrm{~h}$, washed with Perm/wash, and incubated with anti-caspase-3-FITC at $4{ }^{\circ} \mathrm{C}$ for $1 \mathrm{~h}$. Data were acquired using a MACSQuant Analyzer 10 cytometer and analyzed with FlowJo software. Cells cultured in a medium without inhibitors and anti-IgM F(ab)2 were used to compare PRL-induced apoptosis. 


\subsection{Statistical Analysis}

The results were analyzed according to the distribution of the data (average and deviation). The Shapiro-Wilks normality test was used to determine the distribution of data. The quantitative independent variables were compared using the paired $t$-test. Differences between groups were determined using the ANOVA test. A value of $p<0.05$ was considered significant; statistical analysis of the data was performed using SPSS Statistics 27 software (IBM, Armonk, NY, USA).

\section{Results}

3.1. Immature B Cells from Mice and WEHI-231 Cells Express the Long Isoform of the PRL Receptor

PRL can activate different cellular signaling pathways depending on the receptor isoform that is expressed. We determined the PRL receptor isoform expressed in BM B cells from the C57BL/ 6 control and lupus-prone MRL/lpr mice at 9 weeks of age. Here, we used bulk BM B cells and observed that only the long isoform was expressed (Figure 1A); the same was observed in WEHI-231 cells (Figure 1B). B cells in different stages of BM maturation were purified by sorting (Figure 1C), and we confirmed that only the long PRL receptor isoform was expressed throughout each stage of maturation in mice at 9 and 15 weeks of age. In C57BL/ 6 mice, we observed that the expression of the long isoform decreased as the B cell matured: 9-week-old mice, pro-B $0.050 \pm 0.015$, pre-B $0.044 \pm 0.009$, and immature $0.010 \pm 0.004$; 15 -week-old mice, pro-B $0.057 \pm 0.008$, pre-B $0.029 \pm 0.016$, and immature $0.010 \pm 0.003$ (Figure 1D). In the MRL/lpr strain, we observed than the pro-B cells $(0.012 \pm 0.003)$ and immature $B$ cells $(0.011 \pm 0.004)$ showed higher expression than pre-B cells $(0.004 \pm 0.004)$ (Figure 1E). Moreover, in 15-week-old MRL/lpr mice, in which elevated PRL levels have been documented [10,11], an increase in the expression of the long isoform was found in all populations that was greater in immature B cells (pro-B $0.067 \pm 0.007$, pre-B $0.061 \pm 0.00$, and immature $0.130 \pm 0.024$ ) (Figure 1E, Figure S1). In summary, only the long isoform of the PRL receptor was observed, and immature B cells were the stage of differentiation in which higher levels of expression were observed in lupus-prone MRL/lpr mice.

3.2. PRL Activates STAT3 in Immature B Cells from MRL/lpr Mice, Whereas in WEHI-231, It Activates the PI3K/AKT and STAT3 Signaling Pathways

We then determined the signaling components associated with the PRL receptor upon activation with recombinant PRL in immature B cells isolated from 9-week-old control and MRL/lpr mice. Since the JAK-STAT pathway is known to be activated by the long receptor isoform, we determined whether PRL activates the STAT kinases through STAT phosphorylation by flow cytometry. We found that PRL induced phosphorylation of STAT3 (pSTAT3) in MRL/lpr mice and confirmed this activity with an inhibitor of the PRL receptor (G129R) and a STAT3 inhibitor (Stattic). The pSTAT3 was measured by mean fluorescence intensity (MFI) and the percentage of positive cells (medium $30.12 \pm 5.90 \mathrm{MFI}, 5.98 \pm 0.35 \%$; PRL $42.85 \pm 13.18$ MFI, $10.45 \pm 0.35 \%$; G129R $30.13 \pm 2.43$ MFI, $5.53 \pm 1.050 \%$; Stattic $24.50 \pm 2.73 \mathrm{MFI}, 5.72 \pm 0.45 \%$ ) (Figure 2A-C). In addition, PRL activity was more prominent in MRL/lpr immature B cells, since in the lupus-prone strain only, the inhibitors significantly reduced pSTAT3 (Figure 2A). PRL did not activate STAT1, STAT5, AKT, or ERK phosphorylation in control or MRL/lpr mice. In agreement, no significant variations were observed in the activation of these kinases when we used the PRL inhibitor or Stattic (Figure S2A-D). 
A)

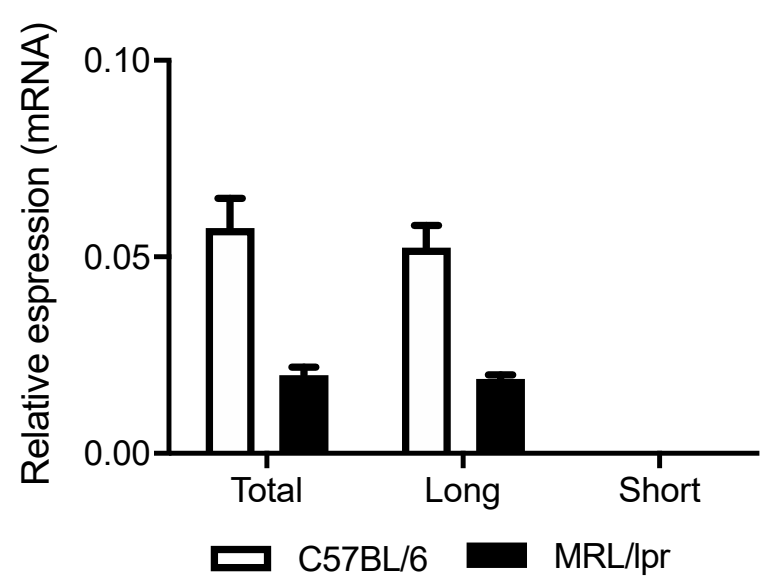

C)

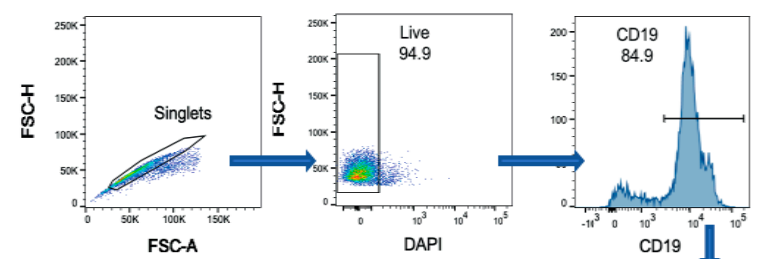

FSC-A

Pre-Sort
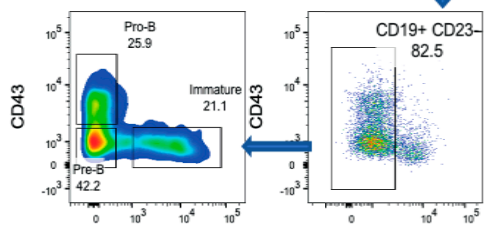

ogt-Sort

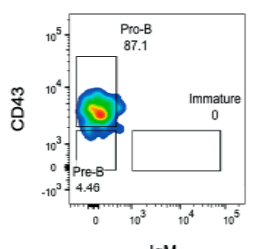

IgM

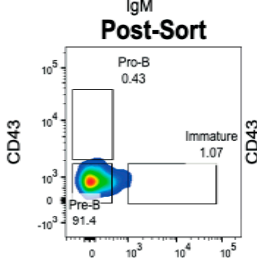

lgM
Pre B cell

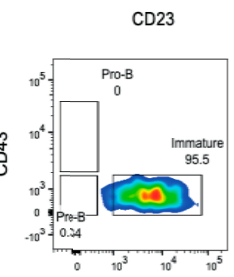

lgM
Immature $B$ cells
B)

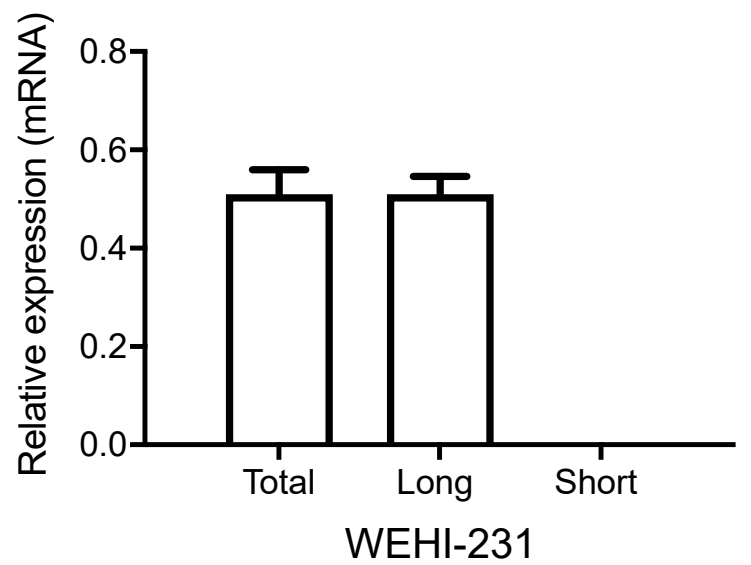

D)

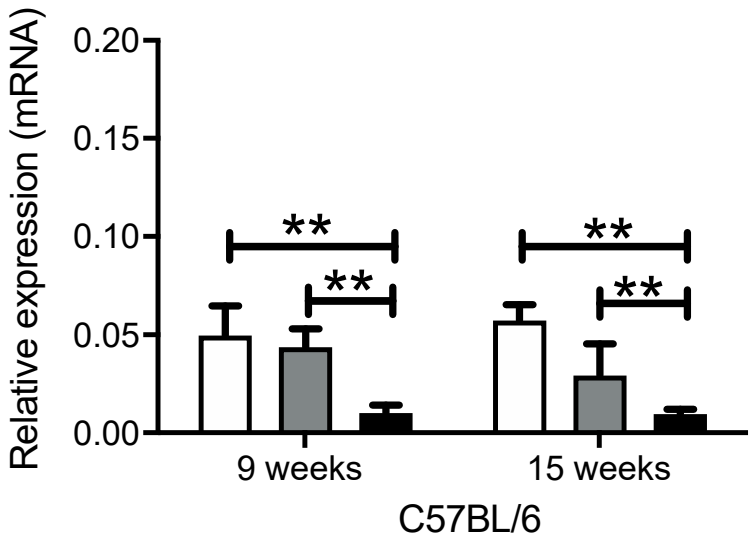

E)

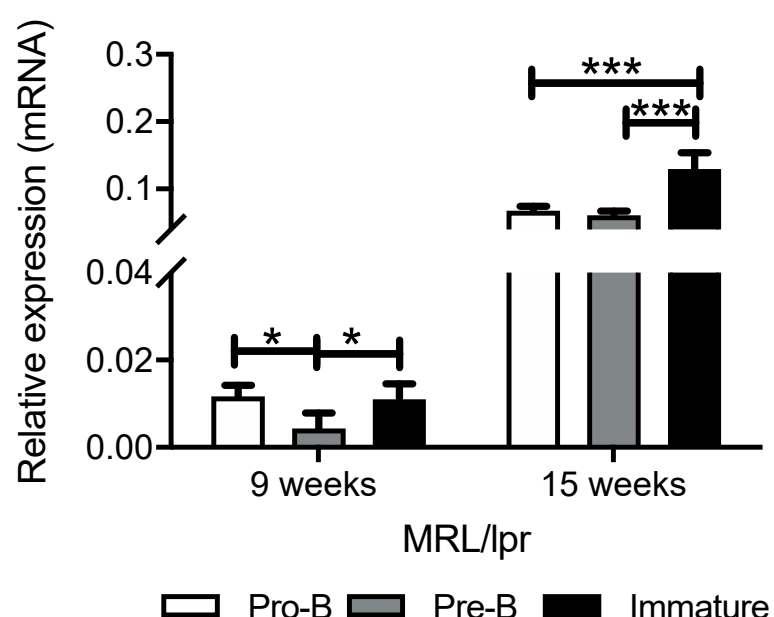

Figure 1. Relative expression of the long prolactin (PRL) receptor isoform. Bulk bone marrow (BM) B cells, and pro-B, pre-B, and immature-B cells were purified through flow cytometry and subjected to real-time (RT) PCR to determine the relative expression and identity of the PRL receptor isoforms. (A) Expression of the long and short isoforms in bulk BM B cells from C57BL/ 6 and MRL/lpr mice (the murine breast cancer cell line EpH4 1424 was used as positive control for expression of the long and short PRL-receptor isoforms), and (B) in the WEHI-231 cell line. (C) Demonstration of the gating strategy for sorting. Doublets were excluded by gating on FSC-H $\times$ FSC-A, and live cells were gated in the DAPI negative, and with the CD23 negative gate we excluded all mature recirculating B cells; Pro-B cells (CD43+IgM-), Pre-B cells (CD43-IgM-) and immature B cells (CD43-IgM+) were sorted. (D) Expression of the PRL isoforms in pro-B, pre-B, and immature B cells from C57BL/ 6 mice at 9 and 15 weeks of age and (E) in MRL/lpr mice. Three independent experiments were conducted and a pool of three mice was used in each experiment. Pooled data are presented as mean \pm SD. ${ }^{*}, p<0.05 ;{ }^{* *}, p<0.01$; and $* * *, p<0.005$ using one-way analysis of variance (ANOVA). 
A)

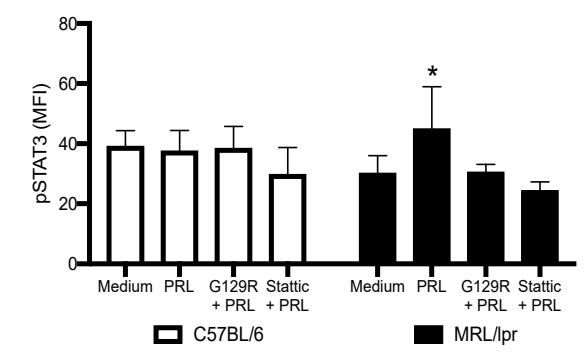

C)

D)

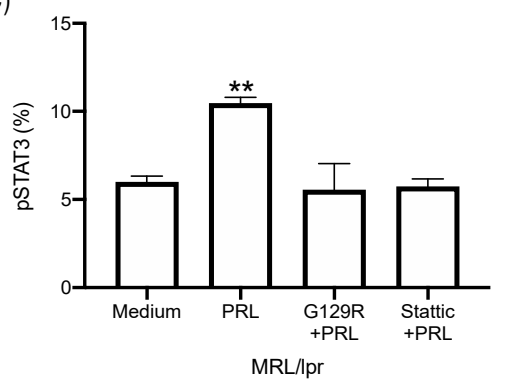

F)

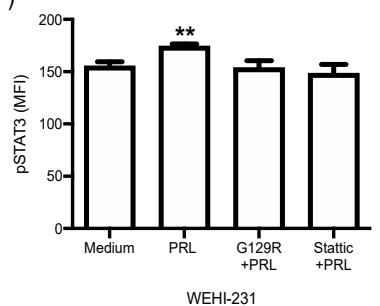

B)

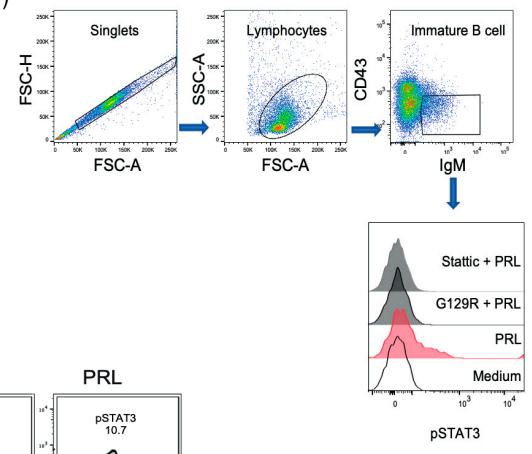

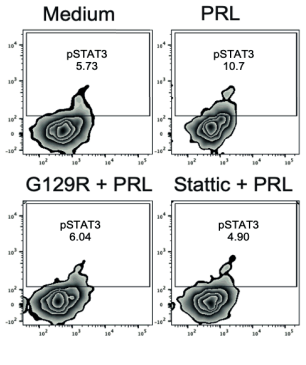

E)
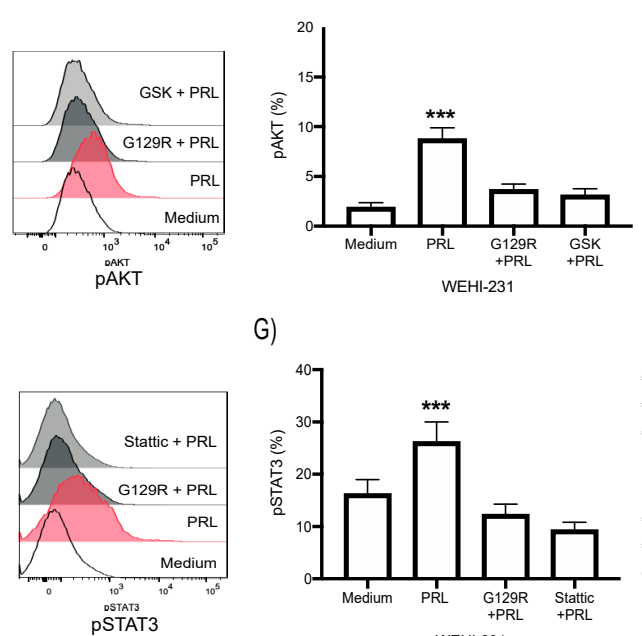

G)

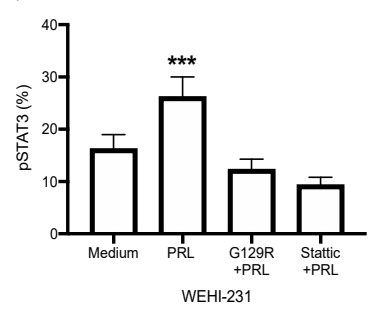

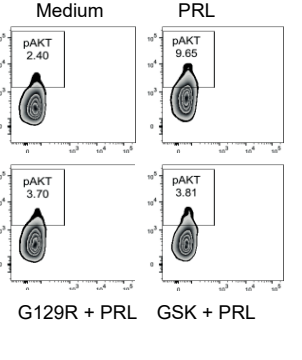

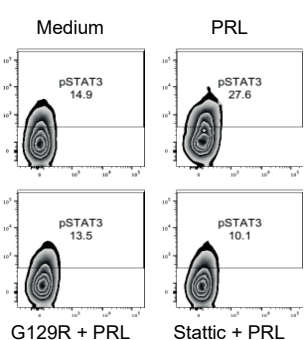

Figure 2. Analysis of the signaling pathways activated by PRL in immature B cells. (A) BM B220+CD23- cells purified by MACS Cell Separation from 9-week-old C57BL/6 and MRL/lpr mice were preincubated for 30 min with the following inhibitors of: PRL receptor (G129R) and STAT3 (Stattic). The cells were then incubated for 30 min with PRL and stainedwith anti-CD43, anti-IgM, and anti-pSTAT3 to subsequently determine the median fluorescence intensity (MFI) of phosphorylation of pSTAT3 in immature B cells (CD43-IgM+). Four independent experiments were performed, and each experiment was conducted in triplicate. Pooled data are presented as means \pm standard deviation (SD). ${ }^{*} p<0.05$ using ANOVA. (B) Demonstration of the gating strategy for the flow cytometric analysis of pSTAT3 in immature B cells. Doublets were excluded by gating on FSC-H $\times$ FSC-A and lymphocytes were identified by their scatter properties (FSC-A $\times$ SSC-A plot). The surface CD43-IgM+ population represents immature B cells. The histogram shows one experiment representative of pSTAT3 in MRL/lpr immature B cells. (C) Percentage of STAT3 positive immature B cells in MRL/lpr mice. Pooled data are presented as means $\pm \mathrm{SD} ;{ }^{* *}, p<0.01$ using ANOVA. A zebra plot of one representative pSTAT3 experiment is shown (right). (D,E) WEHI-231 cells were preincubated for $30 \mathrm{~min}$ with G129R, Stattic, and GSK inhibitors and then incubated 30 min with PRL to determine the phosphorylation of AKT. (D) MFI graph and a histogram from one representative experiment; (E) graph of percentages of positive cells and a zebra plot. $(\mathrm{F}, \mathrm{G})$ Phosphorylation of STAT3 shown as an MFI graph and histogram (F), and graph of percentages and a zebra plot (G). Four different experiments were performed, each in triplicate. Pooled data are presented as means \pm SD. ${ }^{* *}, p<0.01$ and ${ }^{* * *}, p<0.005$ using ANOVA. 
Although PRL induced pAKT in WEHI-231 cells (medium $345.3 \pm 6.56 \mathrm{MFI}, 1.88 \pm 0.40 \%$; PRL 400.00 \pm 41.80 MFI, $8.73 \pm 0.94 \%$; G129R $312.83 \pm 29.68$ MFI, $3.63 \pm 0.50 \%$; GSK, 247.4 $\pm 44.20 \mathrm{MFI}, 3.10 \pm 0.55 \%$ ) (Figure 2D,E), a similar pattern of PRL activation of the signaling pathways was observed. PRL increased the levels of pSTAT3 (medium $155.0 \pm 4.58$ MFI, $16.23 \pm 2.24 \%$; PRL $174.0 \pm 2.64 \mathrm{MFI}, 26.17 \pm 3.15 \%$ ) that was reduced with other inhibitors (G129R 153.3 $\pm 7.23 \mathrm{MFI}, 12.23 \pm 1.66 \%$; Stattic $148.0 \pm 8.88 \mathrm{MFI}, 9.23 \pm 1.21 \%$ ), as shown in Figure 2F,G, but no increase was observed in pSTAT1, pSTAT5, and pERK (Figure S2E-G). These results support the hypothesis that PRL signals through STAT3 in immature B cells of MRL/lpr mice, which was confirmed in WEHI-231 cells, although in the latter, we also observed AKT activation.

\subsection{The Pattern of PRL-Regulated Genes Correlates with Antiapoptotic Activity and Places STAT3 as a Central Transcription Factor}

We have previously reported that PRL protects WEHI-231 cells from BCR cross-linkinginduced apoptosis [12]. Here, we assessed whether PRL also alters apoptosis-related genes ex vivo in immature B cells isolated from MRL/lpr and C57BL/ 6 control mice. For this, we tested the gene expression array $\mathrm{RT}^{2}$ Profiler ${ }^{\mathrm{TM}}$ PCR Array Mouse apoptosis, which measures the expression of 84 genes related to death domain receptors, DNA damage and repair, extracellular apoptotic signals, and many other gene intermediaries and effectors of the apoptosis cascade. An unsupervised clustering based on genes with altered expression segregated mouse strains (Figure $3 \mathrm{~A}$ ). We proceeded to evaluate each strain independently, comparing the PRL condition against the unstimulated controls (Figure 3B,C). Upregulation of the antiapoptotic genes Bcl2l2 (Bcl-w), Bcl2a1a (A1/Bfl-1), Naip1 (Birc1), and Birc5 (survivin) was observed in MRL/lpr immature B cells, and downregulation of many proapoptotic genes. A more divergent result was observed in C57BL/ 6 cells, with both antiapoptotic and proapoptotic genes upregulated and downregulated. However, Birc5 was upregulated in both mouse strains (Figure 3D).
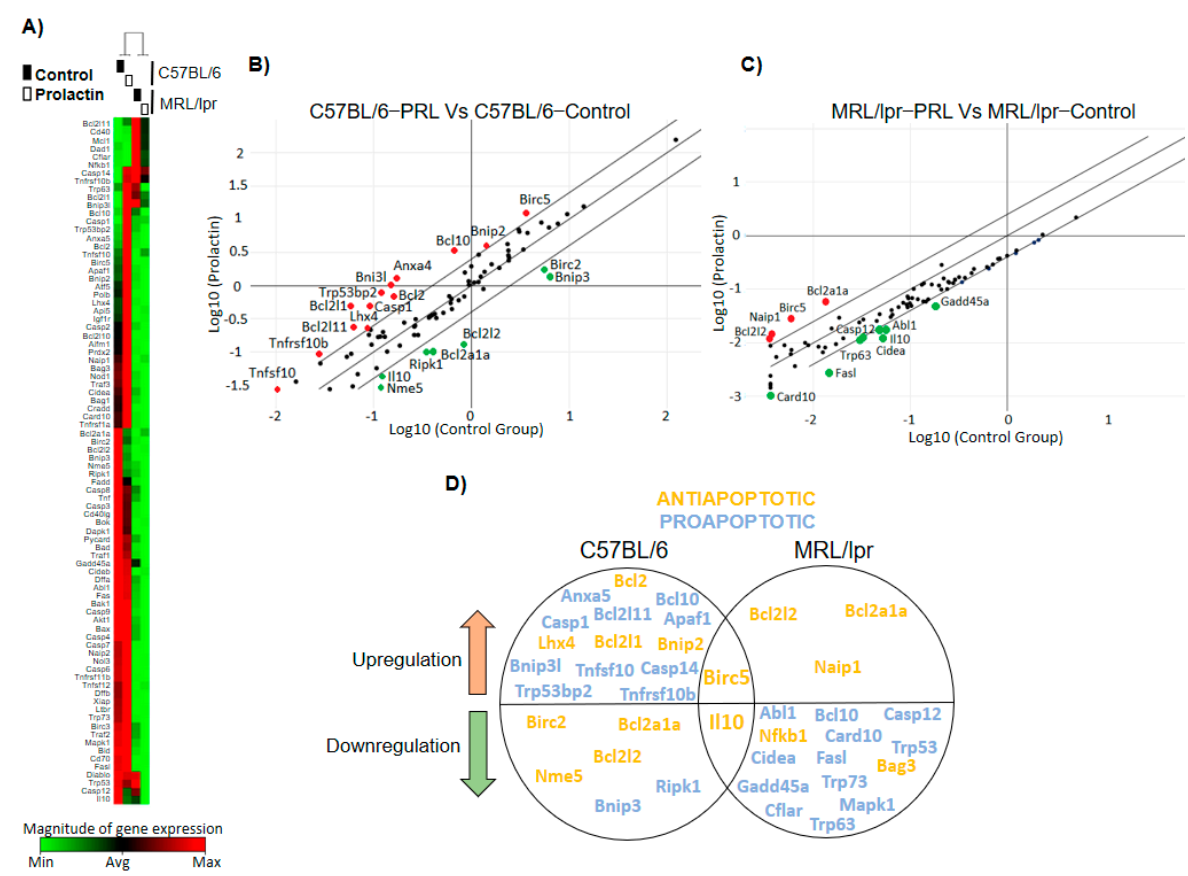

D)

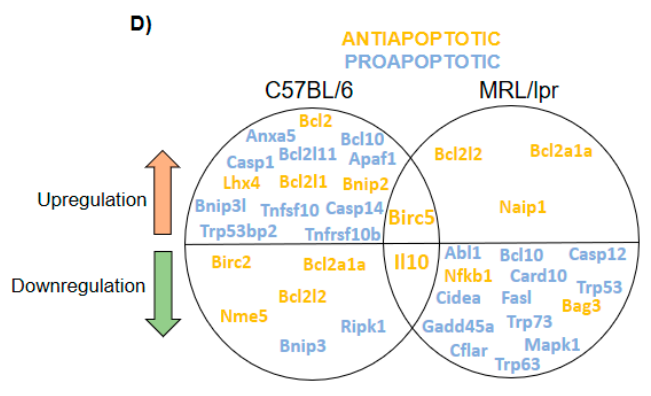

Figure 3. Apoptosis-related genes commonly regulated by PRL in MRL/lpr and C57BL/6 mice. Immature B cells from 9-week-old C57BL/ 6 and MRL/lpr mice were incubated for $30 \mathrm{~min}$ with or without PRL. After stimulation, the expression of 84 genes related to apoptosis was determined. (A) Unsupervised heat map and clustergram of genes transcriptionally altered by the experimental conditions. Scatter plot of genes differentially expressed after PRL stimulation in immature B cells from (B) C57BL/6 and (C) MRL/lpr mice. Red and green dots in (B,C) represent upregulated and downregulated genes, respectively. (D) Venn diagram representing differentially expressed genes shared by both mouse strains. 
To assess the specific genes that were altered in MRL/lpr mice, we compared the PRL-altered genes against all additional conditions, such as unstimulated cells, plus the conditions of inhibition of the PRL receptor (G129R), and STAT3 (Stattic). An unsupervised clustergram showed a closer association between PRL and unstimulated cells than to the inhibitor conditions, probably suggesting the basal activity of the PRL receptor in MRL/lpr immature B cells (Figure 4A). A comparison of genes altered through PRL against all the other conditions showed upregulation of the antiapoptotic genes Birc5 and Bcl2a1a and downregulation of proapoptotic genes Casp8, Gadd45a, and Trp53bp2, consistent with the protective role of self-reactive immature B cells (Figure 4B). A supervised clustergram also highlighted this set of genes, sharply separating PRL-activated cells from inactive cells (Figure 4C). All the genes that changed with the PRL stimuli are shown in Figure 4D. We confirmed the upregulation of Birc5 by RT-PCR and that Bcl2L1 (Bcl-xL) expression was not altered (Figure 4E).

A)

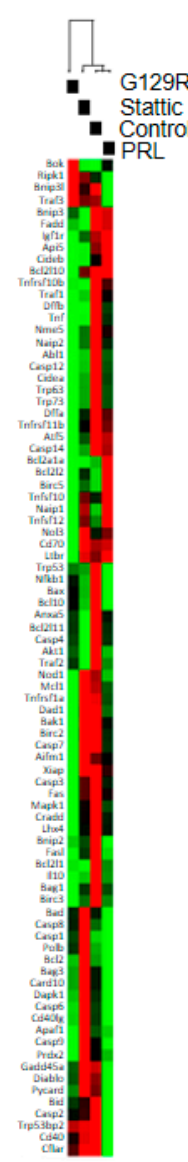

Magnitude of gene expression

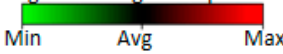

B)

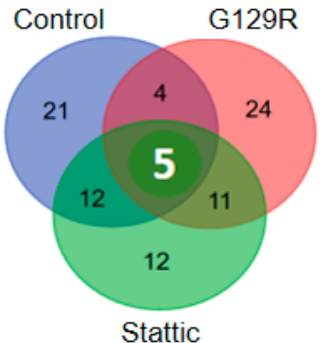

\begin{tabular}{|c|c|}
\hline ANTIAPOPTOTIC \\
\hline Gene & PROAPOPTOTIC \\
\hline Birc5 & Fold regulation \\
\hline Bcl2a1a & 4.38 \\
Casp8 & 7.31 \\
Gadd45a & -3.64 \\
Trp53bp2 & -3.21 \\
\hline
\end{tabular}

C)
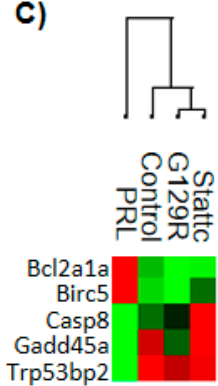

D) $\quad \mathrm{MRL} / \mathrm{pr}-\mathrm{PRL}$

MRL/lpr-Control and inhibitors

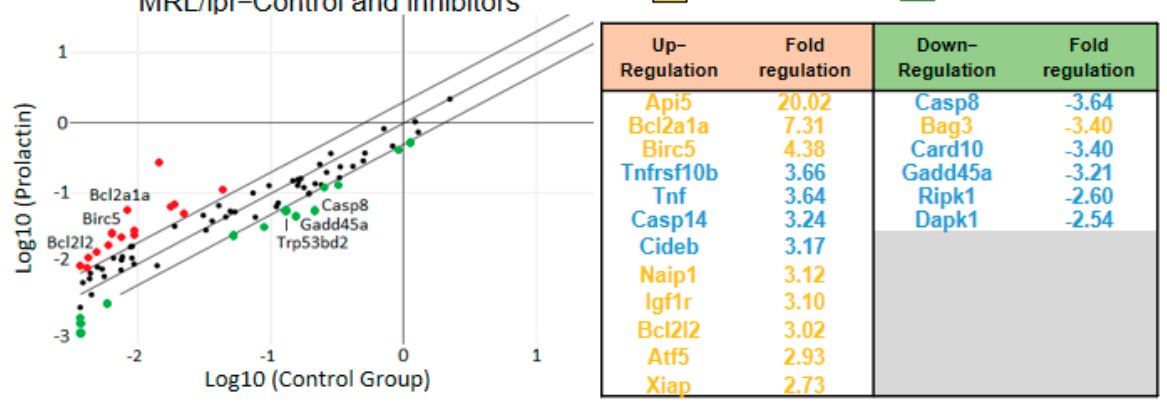

E)

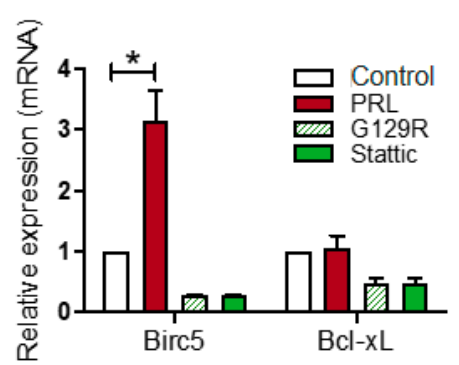

Figure 4. PRL regulation of apoptosis-related genes in MRL/lpr mice. Immature B cells from 9-week-old MRL/lpr mice were preincubated for $30 \mathrm{~min}$ with G129R or Stattic and stimulated for $30 \mathrm{~min}$ with PRL. Expression of apoptosis-related genes was determined in the PRL condition vs. the unstimulated and inhibitor conditions. (A) Unsupervised heat map and clustergram of genes transcriptionally altered by the experimental conditions. (B) Venn diagram and (C) heat map representing genes shared by control, G129R, and Stattic conditions and differentially expressed with respect to the PRL stimulation condition. (D) Scatter plot of genes differentially expressed in supervised analysis of PRL stimulation compared with control, G129R, and Stattic conditions. Red and green dots represent upregulated and downregulated genes, respectively. (E) Validation of PRL-induced Birc5 and Bcl2l1 (Bcl-xL) upregulation using RT-PCR. Three independent experiments were performed and a pool of two mice was used in each experiment. Pooled data are presented as means \pm SD. ${ }^{*}, p<0.05$ using ANOVA. In (B,D), the identity, fold change, and apoptotic function of the altered genes are shown in tables. 
We inferred the main transcription factors activated by PRL in MRL/lpr mice using the list of genes in Figure 4D; we observed that STAT3 was a central transcription factor regulating most of the genes in the list, four upregulated and five downregulated (Figure 5A-C). The transcription factors with the highest enrichment scores were STAT3, NFKB2, HIF1A, and E2F7 among the upregulated genes, and STAT3 and DDIT3 among the downregulated genes (Figure 5A). Protein-protein interaction networks were built using the transcription factors and targeted genes, for both the set of upregulated and downregulated genes independently (Figure 5B,C). This analysis confirmed the centrality of STAT3 and its direct influence on multiple genes, including Birc5, Casp8, and Gadd45a, three genes that were commonly altered by the control conditions (Figure 4B). A functional enrichment analysis using STRING placed the negative regulation of apoptosis as the second most important term of the upregulated protein-protein interaction network and the extrinsic apoptotic signal as the sixth term of the downregulated network (Figure 5B,C). STAT3 and Birc5 appeared as part of the network that negatively regulated apoptosis.

A)

\begin{tabular}{|c|c|c|c|}
\hline \multicolumn{2}{|c|}{ Upregulation } & \multicolumn{2}{c|}{ Downregulation } \\
\hline TF & $\begin{array}{c}\text { No. of } \\
\text { target } \\
\text { genes }\end{array}$ & TF & $\begin{array}{c}\text { No. of } \\
\text { target } \\
\text { genes }\end{array}$ \\
\hline NACC2 & 1 & MYRFL & 1 \\
\hline ZNF816 & 1 & HES1 & 3 \\
\hline HMGA2 & 3 & DDIT3 & 2 \\
\hline MTF2 & 4 & KLF6 & 4 \\
\hline NFKB2 & 4 & GCM1 & 2 \\
\hline AHRR & 3 & NR3C2 & 1 \\
\hline MBD4 & 5 & STAT3 & 5 \\
\hline GTF2B & 3 & \multicolumn{1}{|r}{} \\
\hline ZNF354A & 3 & \multicolumn{1}{|}{} \\
\hline E2F7 & 3 & \\
\hline HIF1A & 3 & \\
\hline STAT3 & 4 &
\end{tabular}

C)

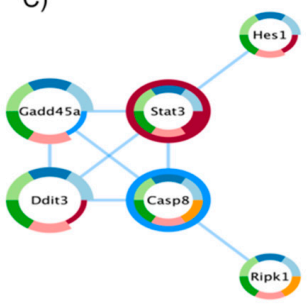

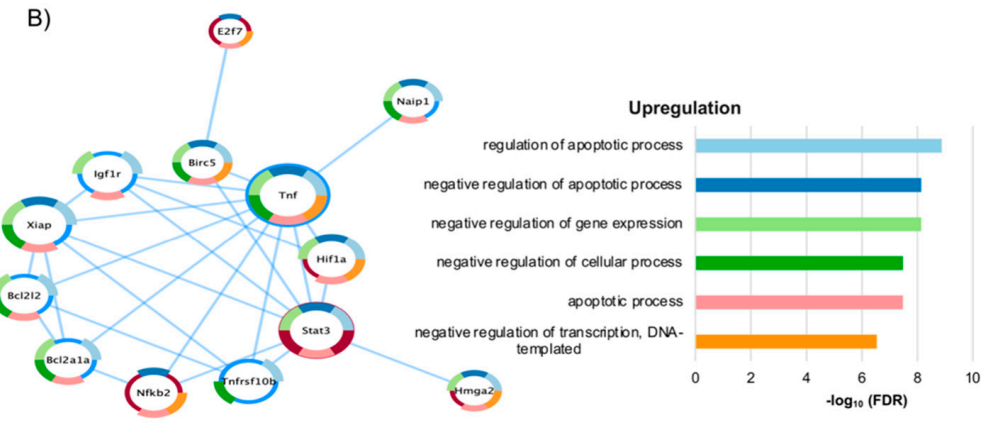

D)

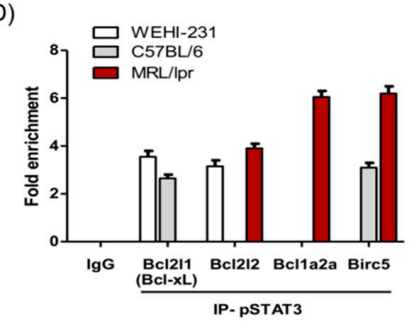

Figure 5. Bioinformatics and chromatin immunoprecipitation analyses of the transcriptional regulation of the apoptosis resistance genes. (A) Predicted transcription factor enrichment based on differentially expressed genes upon PRL activation of MRL/lpr immature B cells from 9-week-old mice. Protein-protein interaction networks generated using the set of transcription factors and the related upregulated genes $(\mathbf{B})$ or the set of transcription factors and the related downregulated genes $(\mathbf{C})$ as input. The size and border width of the nodes represent closeness centrality and betweenness centrality, respectively; the nodes with a red border are central transcription factors, nodes with blue borders are the direct genes under the transcription factor regulation, and donut charts represent gene ontology processes enriched in the networks. (D) pSTAT3 ChIP of immature B cells from 9-week-old C57BL/6 and MRL/lpr mice and WEHI-231 cells after stimulation for $1 \mathrm{~h}$ with PRL. The plot represents the fold enrichment at different antiapoptotic gene promoter sites.

\section{4. pSTAT3 Binds to Promoters of the Bcl2 Family and Birc5 of Antiapoptotic Genes}

We used the ChIP assay to determine the binding of pSTAT3 to the promoter sites of antiapoptotic genes that were central in this study. We chose Bcl2l1, a gene previously observed in our analysis of WEHI-231 cells [12], and also in C57BL/6 immature B cells (Figure 3D), and Bcl2l2, Bcl2a1a, and Birc5, some of the most central genes in the analysis of MRL/lpr cells (Supplementary Table S2). We corroborated the binding of pSTAT3 to the promoters of Bcl2l1 (2.65 \pm 0.21 fold enrichment) and Birc5 genes (3.10 \pm 0.28 fold enrichment) in PRL-stimulated immature B cells from C57BL/6 mice, whereas in MRL/lpr mice, pSTAT3 bound to the promoter sites of $B c l 2 l 2$ (3.90 \pm 0.28 fold enrichment), Bcl2a1a (6.05 \pm 0.35 fold enrichment), and Birc5 (6.20 \pm 0.42 fold enrichment) genes (Figure 5D). In 
the WEHI-231 line, we observed that PRL induced the binding of PSTAT3 to the promoters of Bcl2l1 (3.55 \pm 0.35-fold enrichment) and Bcl2l2 genes ( $3.15 \pm 0.35$-fold enrichment).

\subsection{Prolactin Rescues Immature B Cells from Apoptosis via the STAT3 Pathway}

To confirm that PRL signaling through STAT3 was responsible for rescuing immature B cells from apoptosis, we performed apoptosis assays (determined as the percentage of caspase-3 positive cells) in the presence of G129R (PRL-inh) as well as Stattic (STAT3 inhibitor). We observed that PRL rescued cells from apoptosis induced by BCR crosslinking with anti-IgM antibodies in MRL/lpr mice but not in C57BL/ 6 mice. When the PRL signal was inhibited, the effect of the hormone was reversed (MRL/lpr medium $19.17 \pm 1.88$; anti-IgM F $\left(\mathrm{ab}^{\prime}\right)_{2} 47.26 \pm 4.60$; PRL $34.60 \pm 0.82 ;$ G129R $51.90 \pm 2.83$; Stattic $52.07 \pm 3.49$ ) (Figure 6A). In C57BL/ 6 control mice, we observed a nonsignificant increase in apoptosis with the STAT3 inhibitor (Figure 6B). As we have previously reported [12], PRL rescued the WEHI-231 cells from apoptosis and the rescue was also abolished with the inhibitors (medium $31.17 \pm 0.25$; anti-IgM F $\left(\mathrm{ab}^{\prime}\right)_{2} 84.40 \pm 2.15$; PRL $78.11 \pm 0.32$; G129R $83.87 \pm 1.52$; Stattic $83.5 \pm 0.10$ ) (Figure 6C).

A)

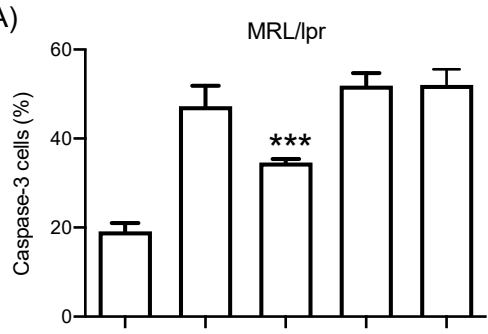

B)

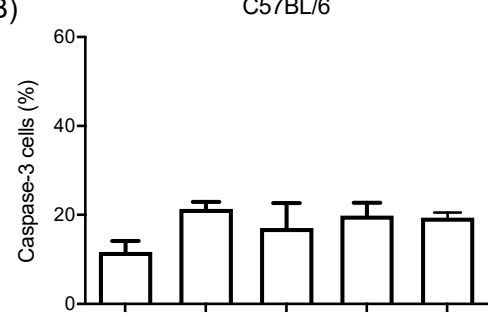

C)

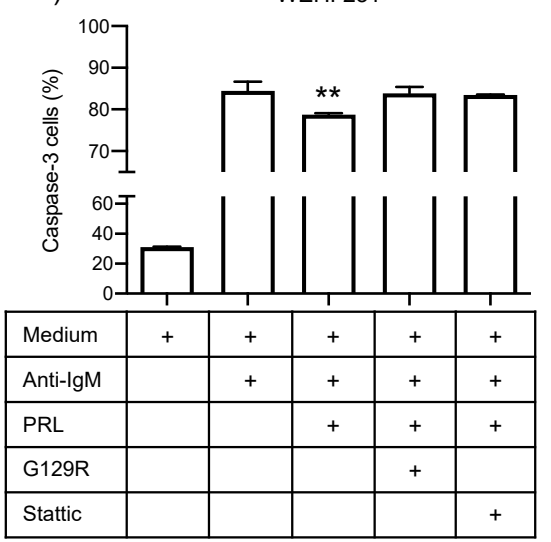

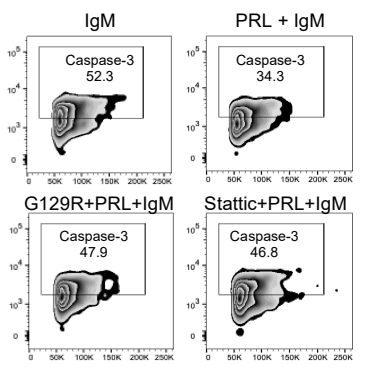

IgM
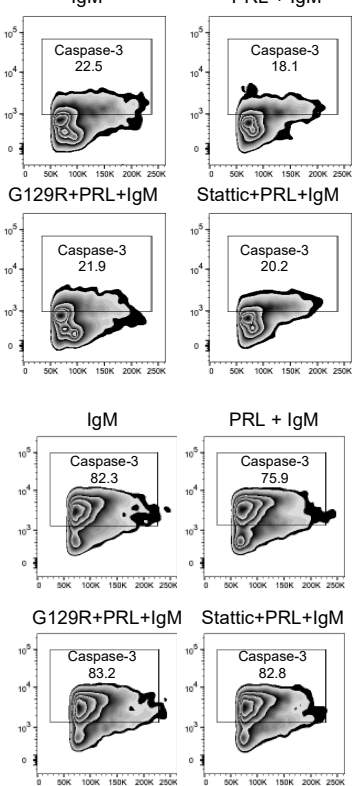

Figure 6. Effect of PRL receptor signaling on immature B cell apoptosis. Purified immature B cells from 9-week-old MRL/lpr (A) and C57BL/ 6 mice (B), and WEHI-231 cells (C) were activated for $1 \mathrm{~h}$ with PRL after either PRL receptor (G129R) or STAT3 (Stattic) signaling inhibition (30 min), and then incubated with anti-IgM antibody to induce BCR cross-linkingmediated apoptosis. Zebra plots represent the percentage of caspase-3-positive apoptotic cells. Four different experiments were performed in triplicate. Pooled data are presented as means \pm SD. ${ }^{* *}, p<0.01, * * *, p<0.005 ;$ using ANOVA. 


\section{Discussion}

The role of PRL in apoptosis inhibition in cells of the immune system such as thymocytes [25] and T cells [26], and during B cell maturation in the BM [27], as well as in breast [26] and ovarian [28] cancer cells has been previously documented. Moreover, somatic gain-of-function STAT3 mutations are exclusive to T, NK, and B cell malignancies [29]. We have also documented the ability of PRL to rescue the immature B cells and WEHI-231 cell line from BCR cross-linking-induced apoptosis [12], which is an experimental scheme that mirrors the elimination of self-reactive clones and has been extensively studied as a model of B cell tolerance (clonal deletion). Nevertheless, the molecular mechanism through which PRL exerts antiapoptotic effects in these cells and how this hormone influences the development of SLE remain unclear. In this study, we have presented evidence for a novel mechanism, demonstrating, for the first time, that all stages of B cell maturation in the BM exclusively express the long isoform of the PRL receptor, both in lupus-susceptible and nonsusceptible mice. We also found that the PRL receptor expression increases with B cell maturation in lupus-susceptible mice, being the highest in immature B cells and coinciding with the time of the onset of the disease, which supports a mechanism of protection against the clonal deletion of autoreactive clones. Protection against the apoptosis of cancer cells is also mediated by the long isoform of the PRL receptor [28].

Our data support that PRL prevents immature B cell clonal deletion through STAT3 signaling, since its inhibition affected PRL functional activity and STAT3 was the most central transcription factor in the bioinformatic analysis. We did not find evidence of AKT or ERK activation, as these kinases were not phosphorylated upon PRL treatment. Furthermore, ERK was also included in the set of genes analyzed by the array and its expression was not altered. In contrast, we found that in WEHI-231 cells, PRL signals through STAT3 and PI3K-AKT. PRL signaling through multiple pathways has been described for other cell lines, such as PI3K-AKT and STAT in Nb2 rat lymphoma cells [30,31], and STAT5, AKT, and ERK1/2 in T47D breast cancer cells [32]. Differential PRL pathway activation may be influenced by the isoform of the receptor expressed and by the tyrosine residue(s) phosphorylated upon receptor activation. The intracellular domain (IC) of the PRL receptor long isoform contains several tyrosine residues. The phosphorylation of IC tyrosines creates binding sites for $\mathrm{SH} 2$ domain-containing signaling proteins. The specificity of $\mathrm{SH} 2$ proteins binding to phospho-tyrosines is influenced by the surrounding amino acid sequences [33].

Further support for the antiapoptotic effect of PRL through STAT3 was found through the use of the STAT3 inhibitor Stattic. Both Stattic and PRL-inh, which is a prolactinbased peptide containing a G129R mutation that acts as an antagonist of the PRL receptor, increased the frequency of apoptotic caspase-3 positive immature B cells. Remarkably, PRL seems to solely counteract negative selection in the SLE-susceptible MRL/lpr mice. Although immature B cells from C57BL/ 6 mice also express the long PRL receptor isoform, PRL could not rescue them from BCR cross-linking-induced apoptosis. This may have different possible explanations: while the protein expression of the PRL receptor decreased in immature B cells from C57BL/ 6 mice, it increased and was higher in MRL/lpr mice (Supplementary Figure S1) [11], rendering PRL signaling insufficient to counteract death signals in the former. This has been observed in humans, where $\mathrm{T}$ cells from patients with SLE express higher levels of the PRL receptor than those from healthy subjects; upon activation with anti-CD3/CD28 plus PRL, increased IFN $\gamma$ secretion is only observed in the T cells of patients with SLE [34]. Similarly, PRL-induced signaling was only observed in colon cancer cells and cell lines with a higher PRL receptor expression than in normal colonic epithelial cells [35].

PRL seems to counteract clonal deletion signals through a complex pattern of transcription in which there is a synchronized upregulation of several antiapoptotic genes and downregulation of proapoptotic genes. The transcriptional and gene network analyses identified Birc5, Bcl2a1a, Bcl2l2, Xiap, Igf1r, Trp53bp2, and Naip1 among the antiapoptotic genes whose expression was significantly enhanced, and Casp 8 and Gadd $45 a$ among the proapoptotic genes lost. Notably, although the pattern of genes altered in C57BL/ 6 cells is 
also very complex, there is no clear-cut final outcome, since multiple proapoptotic genes exhibited increased expression and multiple antiapoptotic genes were lost upon PRL activation. Bcl2a1a, Bcl2l2, and Trp53bp2 are among these discordant genes, which are important for rescuing MRL/lpr immature B cells. Therefore, different levels of expression of the PRL receptor at the protein level and a discordant network of the regulation of genes related to apoptosis may explain, on one hand, why we did not observe STAT3 phosphorylation and rescue of apoptosis in C57BL/ 6 immature B cells, and, on the other hand, the capacity of PRL to trigger SLE specifically in individuals with genetic susceptibility.

The experimental and bioinformatics analyses identified STAT3 as the most central transcription factor driving the expression of apoptosis-related genes, but HIF1 $\alpha, \mathrm{NFkB} 2$, E2F7, and HES1 also appeared to participate. The functions of STAT3 in vivo have been extensively studied in both health and disease, particularly in cancer. Most STAT3 target genes are key participants of cell growth, cell cycle progression, survival, transformation, invasion, and metastasis [36-38]. STAT3 activation is also required for the differentiation of B cells into plasma cells [39] and for B cell maturation in BM [27]. The ChIP analysis also confirmed the link between PRL and STAT3, with Bcl2a1a, Bcl2l2, and Birc5. STAT3 activation of Birc5 has been reported in paclitaxel- and cisplatin-resistant ovarian cancer cells, and the abrogation of STAT3 signaling results in a reduced expression of Birc5, circumventing chemoresistance $[40,41]$. Birc5 is also downstream of STAT3 transcription activity in triple-negative breast cancer, and STAT3 binding to the Birc5 promoter has been demonstrated through ChIP analysis [42,43]. STAT3 also induces chemoresistance in diffuse large B-cell lymphomas through a decreased expression of Casp8, among many other genes [44]. STAT3 downregulation of Casp 8 has also been shown in the human leukemia HL-60 cell line [45]. Another neoplasm in which STAT3 has been linked to Birc5 is acute myeloid leukemia (AML). Common mutations in the kinase domain of Flt3 result in the constitutive phosphorylation of STAT3 and increased levels of Birc5 expression, which protects AML cells from apoptosis [46]. All these studies support the association between STAT3 and resistance to apoptosis, and confirm an important role for Birc5 in hematological neoplasms and solid cancers.

An extensive body of evidence links STAT3 with autoimmune diseases. Most of the evidence is related to the capacity of STAT3 to influence the differentiation of lymphoid cells, such as Th17 and Treg CD4 T cells [47]. Indeed, gain-of-function mutations have been reported in patients with autoimmune conditions [48,49]. A different mechanism may operate in STAT3's relationship with SLE, since Stattic inhibition of STAT3 blocked the secretion of autoantibodies from B cells isolated from patients with SLE [50]. Stattics have also been used to delay the onset of disease in MRL/lpr mice, reducing the levels of clinical hallmarks of SLE, such as nephritis, renal and skin lesions, proteinuria, and serum autoantibodies [51,52]. Moreover, inhibitors of JAK2, which is a kinase upstream of STAT3, are currently in clinical trials to treat SLE [53], as well as open clinical trials (NCT03616912 [Last Update 20/01/2021], NCT03616964 [Last Update 19/10/2020]).

Less is known about the contribution of STAT3-induced cell survival for autoimmune diseases and whether $\mathrm{Bcl} 2$ and inhibitor of apoptosis (IAP) family members play a role, as has been documented for cancer cells. We have previously documented increased Birc5 expression in pro-B and immature B cells in an SLE-prone mouse strain, which is associated with high levels of PRL [11]. There is also evidence of $B c l 2 a 1 a, B c l 2 l 2$, and Birc5 expression in bone marrow B cells. For instance, Bcl2l2 and Birc5 expression was observed throughout the small pre-B cell stage but it was lost in immature B cells in mice without an autoimmune disease genetic background [54]. Mice overexpressing Bcl2a1a in the hematologic compartment develop an aggressive malignant disease characterized as leukemia or lymphoma of B cell origin [55]. Bcl2l2 also plays a critical role in B cell survival and lymphomagenesis [56]. In contrast, Birc5 is overexpressed in numerous malignant diseases, as well as in autoimmune diseases, including multiple sclerosis and myasthenia gravis $[57,58]$. 
Collectively, our data suggest that PRL protects autoreactive immature B cells from BCR cross-linking-induced apoptosis through STAT3 and a complex network of apoptosisrelated genes (see Figure 7 for a current working model). Increased PRL levels have been associated with disease activity, and the increased immune complex deposition is a hallmark of the damage to tissues and organs that characterizes SLE. We have previously documented that elevated levels of PRL increase the absolute number of splenic transitional$1 \mathrm{~B}$ cells in MRL/lpr mice [10]. In future studies, it will be important to follow the influence of PRL in the maturation of B cells in secondary lymphoid organs, particularly to understand if PRL facilitates the activation of self-reactive clones and their differentiation into plasma cells, in order to better understand the effect of PRL on the pathogenesis of SLE.

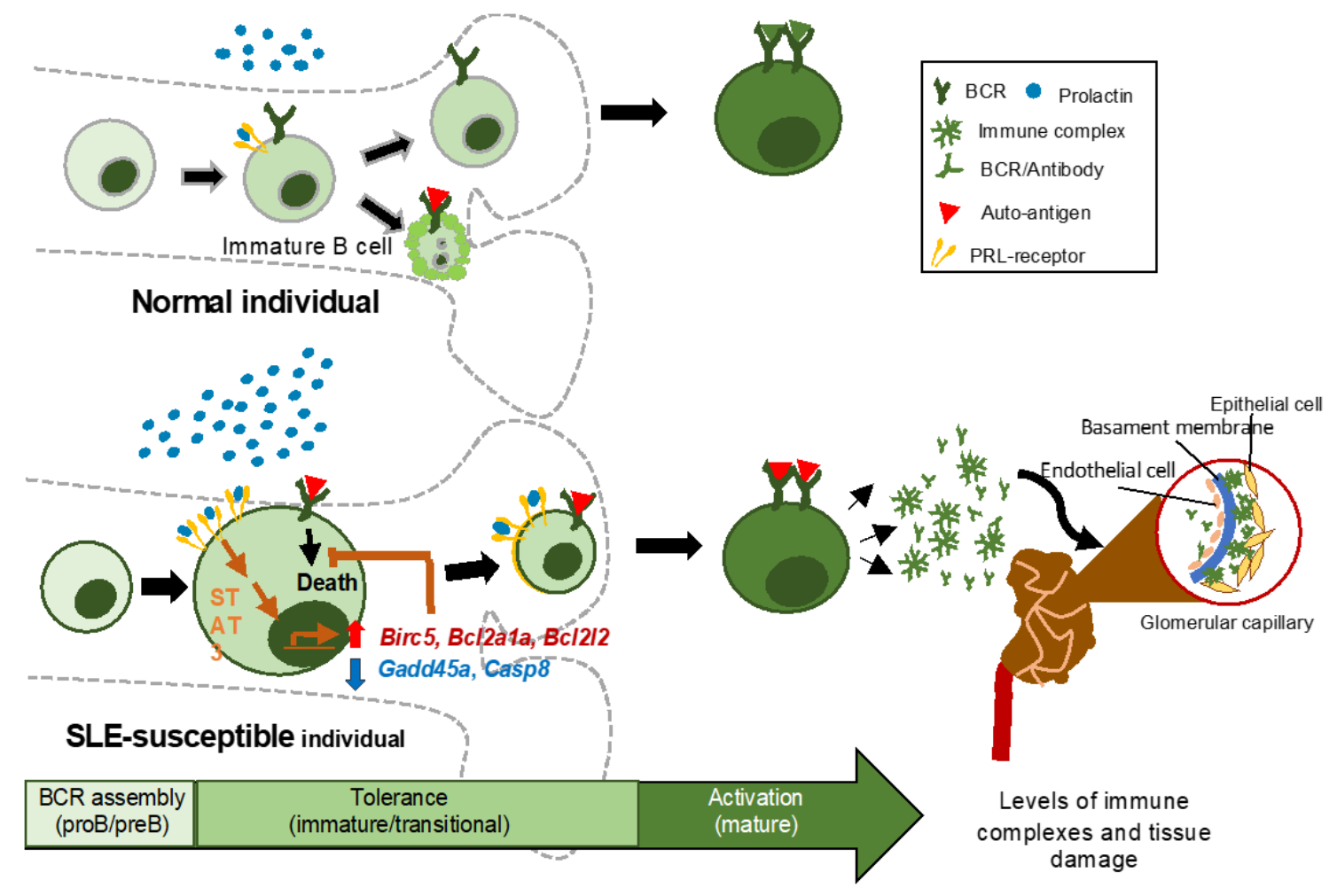

Figure 7. Working model of the mechanism of action of PRL in immature B cells from mice that developed SLE. Immature B cells from SLE-susceptible mice display increased levels of PRL receptor expression restrictive to the long isoform, together with higher levels of serum PRL. This combination results in the heightened activation of STAT3 and altered expression of genes related to the control of apoptosis, such as Birc5, Bcl2a1a, Bcl2l2, Gadd45a, and Casp8, and also of other Bcl2 and inhibitor of apoptosis (IAP) family members, which increase the survival of immature B cells, including those cells undergoing clonal deletion because of rearranged self-reactive antigen receptors. By allowing these autoreactive clones to continue their maturation process and eventually become plasma B cells, PRL contributes to the increased levels of autoantibody and tissue damage due to immune complex deposition that characterize SLE.

\section{Conclusions}

All B cell maturation stages in bone marrow express the prolactin receptor long isoform in both wild-type and MRL/lpr mice, but its expression increased only in the immature B cells of the latter, particularly at the onset of lupus. In these cells, activation of the PRL receptor promoted the phosphorylation of the transcription factor STAT3, demonstrating that it binds to the promoter of the anti-apoptotic genes Birc5, Bcl2a1a, and $B c l 2 l 2$, and confirming that the PRL receptor signaling pathway rescues immature B cells from apoptosis-induced BCR aggregation. 


\section{Limitations of Study}

A limitation of the present study is that we compared the C57BL/6 mouse strain with the MRL/lpr lupus prone strain. The MRL/lpr strain carries a mixed genetic background plus a mutation in the Fas gene. Since the lupus-susceptible MRL-MpJ strain is the closest genetically to MRL/lpr, future experiments should examine PRL's anti-apoptotic function in this strain to assess the influence of Fas on the prolactin-STAT3 axis. Furthermore, although we specifically wanted to assess apoptosis in this study, RNA sequencing would help to unveil the contribution of other mechanisms to the activity of PRL in immature B cells.

Supplementary Materials: The following are available online at https: / www.mdpi.com/2073-4 409/10/2/316/s1, Table S1, Gene expression among the set of housekeeping genes included in the array; Table S2, Ct values of genes Bcl211, Bcl212, Birc5, and Bcl1a2a after immunoprecipitation with anti-pSTAT3 and IgG isotype control of immature B cells from 9-week-old C57BL/ 6 and MRL/lpr mice and WEHI-231 cells after $1 \mathrm{~h}$ stimulation with PRL; Figure S1, PRL receptor expression in immature B cells; Figure S2, Analysis of the signaling pathways activated by PRL in immature B cells and WEHI-231 cells.

Author Contributions: Conceptualization, A.K.C.-R. and E.M.F.-P.; methodology, R.F.-F. and L.C.-S.; validation, A.K.C.-R. and E.M.F.-P.; formal analysis, R.F.-F., A.A.-L., and M.C.S.-A.; investigation, R.F.-F.; resources, P.G.-R. and A.P.-V.; data curation, R.F.-F., A.A.-L., and M.C.S.-A.; writing-original draft preparation, A.K.C.-R.; writing-review and editing, E.M.F.-P.; supervision, A.K.C.-R.; funding acquisition, A.K.C.-R. and F.B.-F. All authors have read and agreed to the published version of the manuscript.

Funding: This work was supported by Fondo de Investigación en Salud IMSS (grant numbers FIS/IMSS/ PROT/G17-2/1709 and FIS/IMSS/PROT/G18/1804), and CONACYT (grant number A1-S-9789).

Institutional Review Board Statement: All studies were approved by the Animal Care Committee of Instituto Nacional de Enfermedades Respiratorias "Ismael Cosio Villegas" and the Coordinación de Investigación en Salud, Hospital de Pedíatria, Centro Medico Nacional Siglo XXI, IMSS (protocol number R-2016-785-019 and R-2017-785-114); all experiments were performed in accordance with approved guidelines establish by Mexico (NOM-062-ZOO-1999) and the NIH Guide for the Care and Use of Laboratory Animals.

Informed Consent Statement: Not applicable.

Data Availability Statement: The data presented in this study are available on request from the corresponding author.

Acknowledgments: We extend our gratitude to the Flow Cytometry core facility, the Coordinación de Investigación en Salud, CMN SXXI, IMSS, for the instrumental and technical support. Angélica Aponte-López is a doctoral student from Programa de Doctorado en Ciencias Biomédicas, Universidad Nacional Autónoma de México (UNAM), and received Fellowship 284102 from CONACYT. M.C.S.A is a PhD student from Programa de Doctorado en Ciencias en Biomedicina y Biotecnología Molecular, Escuela Nacional de Ciencias Biológicas, Instituto Politécnico Nacional, Ciudad de México, Mexico, and received a CONACyT fellowship (No. 576518).

Conflicts of Interest: The authors declare no conflict of interest.

\section{References}

1. Hardy, R.R.; Hayakawa, K. B Cell development pathways. Annu. Rev. Immunol. 2001, 19, 595-621. [CrossRef] [PubMed]

2. Hobeika, E.; Dautzenberg, M.; Levit-Zerdoun, E.; Pelanda, R.; Reth, M. Conditional Selection of B Cells in Mice With an Inducible B Cell Development. Front. Immunol. 2018, 9, 1806. [CrossRef] [PubMed]

3. Nemazee, D. Mechanisms of central tolerance for B cells. Nat. Rev. Immunol. 2017, 17, 281-294. [CrossRef] [PubMed]

4. Yurasov, S.; Wardemann, H.; Hammersen, J.; Tsuiji, M.; Meffre, E.; Pascual, V.; Nussenzweig, M.C. Defective B cell tolerance checkpoints in systemic lupus erythematosus. J. Exp. Med. 2005, 201, 703-711. [CrossRef] [PubMed]

5. Lisnevskaia, L.; Murphy, G.; Isenberg, D. Systemic lupus erythematosus. Lancet 2014, 384, 1878-1888. [CrossRef]

6. Eglys Gómez-Hernández, A.; José García-Mac Gregor, E.; Alfonso García-Montiel, D. Assessment of serum prolactin levels in patients with systemic lupus erythematosus. Investig. Clin. 2016, 57, 237-245.

7. Song, G.G.; Lee, Y.H. Circulating prolactin level in systemic lupus erythematosus and its correlation with disease activity: A meta-analysis. Lupus 2017, 26, 1260-1268. [CrossRef] 
8. Yang, J.; Li, Q.; Yang, X.; Li, M. Increased serum level of prolactin is related to autoantibody production in systemic lupus erythematosus. Lupus 2016, 25, 513-519. [CrossRef]

9. Blanco-Favela, F.; Quintal-Alvarez, G.; Leanos-Miranda, A. Association between prolactin and disease activity in systemic lupus erythematosus. Influence of statistical power. J. Rheumatol. 1999, 26, 55-59.

10. Ledesma-Soto, Y.; Blanco-Favela, F.; Fuentes-Panana, E.M.; Tesoro-Cruz, E.; Hernandez-Gonzalez, R.; Arriaga-Pizano, L.; Legorreta-Haquet, M.V.; Montoya-Diaz, E.; Chavez-Sanchez, L.; Chavez-Rueda, A.K.; et al. Increased levels of prolactin receptor expression correlate with the early onset of lupus symptoms and increased numbers of transitional-1 B cells after prolactin treatment. BMC Immunol. 2012, 13, 11. [CrossRef]

11. Legorreta-Haquet, M.V.; Flores-Fernandez, R.; Blanco-Favela, F.; Fuentes-Panana, E.M.; Chavez-Sanchez, L.; Hernandez-Gonzalez, R.; Tesoro-Cruz, E.; Arriaga-Pizano, L.; Chavez-Rueda, A.K. Prolactin levels correlate with abnormal B cell maturation in MRL and MRL/lpr mouse models of systemic lupus erythematosus-like disease. Clin. Dev. Immunol. 2013, 2013, 287469. [CrossRef] [PubMed]

12. Flores-Fernandez, R.; Blanco-Favela, F.; Fuentes-Panana, E.M.; Chavez-Sanchez, L.; Gorocica-Rosete, P.; Pizana-Venegas, A.; Chavez-Rueda, A.K. Prolactin Rescues Immature B-Cells from Apoptosis Induced by B-Cell Receptor Cross-Linking. J. Immunol. Res. 2016, 2016, 3219017. [CrossRef] [PubMed]

13. Binart, N.; Bachelot, A.; Bouilly, J. Impact of prolactin receptor isoforms on reproduction. Trends Endocrinol. Metab. 2010, 21, 362-368. [CrossRef] [PubMed]

14. Sangeeta Devi, Y.; Halperin, J. Reproductive actions of prolactin mediated through short and long receptor isoforms. Mol. Cell. Endocrinol. 2014, 382, 400-410. [CrossRef] [PubMed]

15. Abramicheva, P.A.; Smirnova, O.V. Prolactin Receptor Isoforms as the Basis of Tissue-Specific Action of Prolactin in the Norm and Pathology. Biochemistry 2019, 84, 329-345. [CrossRef] [PubMed]

16. Devi, Y.S.; Shehu, A.; Stocco, C.; Halperin, J.; Le, J.; Seibold, A.M.; Lahav, M.; Binart, N.; Gibori, G. Regulation of transcription factors and repression of Sp1 by prolactin signaling through the short isoform of its cognate receptor. Endocrinology 2009, 150, 3327-3335. [CrossRef]

17. Pascual-Mathey, L.I.; Rojas-Duran, F.; Aranda-Abreu, G.E.; Manzo, J.; Herrera-Covarrubias, D.; Munoz-Zavaleta, D.A.; Garcia, L.I.; Hernandez, M.E. Effect of hyperprolactinemia on PRL-receptor expression and activation of Stat and Mapk cell signaling in the prostate of long-term sexually-active rats. Physiol. Behav. 2016, 157, 170-177. [CrossRef]

18. Belugin, S.; Diogenes, A.R.; Patil, M.J.; Ginsburg, E.; Henry, M.A.; Akopian, A.N. Mechanisms of transient signaling via short and long prolactin receptor isoforms in female and male sensory neurons. J. Biol. Chem. 2013, 288, 34943-34955. [CrossRef]

19. Creamer, B.A.; Sakamoto, K.; Schmidt, J.W.; Triplett, A.A.; Moriggl, R.; Wagner, K.U. Stat5 promotes survival of mammary epithelial cells through transcriptional activation of a distinct promoter in Akt1. Mol. Cell. Biol. 2010, 30, $2957-2970$.

20. Jabbour, H.N.; Critchley, H.O.; Boddy, S.C. Expression of functional prolactin receptors in nonpregnant human endometrium: Janus kinase-2, signal transducer and activator of transcription-1 (STAT1), and STAT5 proteins are phosphorylated after stimulation with prolactin. J. Clin. Endocrinol. Metab. 1998, 83, 2545-2553. [CrossRef]

21. Roy, G.; Lombardia, M.; Palacios, C.; Serrano, A.; Cespon, C.; Ortega, E.; Eiras, P.; Lujan, S.; Revilla, Y.; Gonzalez-Porque, P. Mechanistic aspects of the induction of apoptosis by lauryl gallate in the murine B-cell lymphoma line Wehi 231. Arch. Biochem. Biophys. 2000, 383, 206-214. [CrossRef] [PubMed]

22. Wen, Y.; Zand, B.; Ozpolat, B.; Szczepanski, M.J.; Lu, C.; Yuca, E.; Carroll, A.R.; Lutgendorf, S.K.; Liu, J.; Sood, A.K.; et al. Antagonism of tumoral prolactin receptor promotes autophagy-related cell death. Cell. Rep. 2014, 7, 488-500. [CrossRef] [PubMed]

23. Schust, J.; Sperl, B.; Hollis, A.; Mayer, T.U.; Berg, T. Stattic: A small-molecule inhibitor of STAT3 activation and dimerization. Chem. Biol. 2006, 13, 1235-1242. [CrossRef] [PubMed]

24. Andersen, C.L.; Jensen, J.L.; Ørntoft, T.F. Normalization of real-time quantitative reverse transcription-PCR data: A model-based variance estimation approach to identify genes suited for normalization, applied to bladder and colon cancer data sets. Cancer Res. 2004, 64, 5245-5250. [PubMed]

25. Krishnan, N.; Thellin, O.; Buckley, D.J.; Horseman, N.D.; Buckley, A.R. Prolactin suppresses glucocorticoid-induced thymocyte apoptosis in vivo. Endocrinology 2003, 144, 2102-2110. [CrossRef] [PubMed]

26. Bauernhofer, T.; Kuss, I.; Friebe-Hoffmann, U.; Baum, A.S.; Dworacki, G.; Vonderhaar, B.K.; Whiteside, T.L. Role of prolactin receptor and CD25 in protection of circulating T lymphocytes from apoptosis in patients with breast cancer. Br. J. Cancer 2003, 88, 1301-1309. [CrossRef]

27. Chou, W.C.; Levy, D.E.; Lee, C.K. STAT3 positively regulates an early step in B-cell development. Blood 2006, $108,3005-3011$. [CrossRef]

28. Asai-Sato, M.; Nagashima, Y.; Miyagi, E.; Sato, K.; Ohta, I.; Vonderhaar, B.K.; Hirahara, F. Prolactin inhibits apoptosis of ovarian carcinoma cells induced by serum starvation or cisplatin treatment. Int. J. Cancer 2005, 115, 539-544. [CrossRef]

29. Zhu, F.; Wang, K.B.; Rui, L. STAT3 Activation and Oncogenesis in Lymphoma. Cancers 2019, 12, 19. [CrossRef]

30. Al-Sakkaf, K.A.; Mooney, L.M.; Dobson, P.R.; Brown, B.L. Possible role for protein kinase B in the anti-apoptotic effect of prolactin in rat $\mathrm{Nb} 2$ lymphoma cells. J. Endocrinol. 2000, 167, 85-92. [CrossRef]

31. Wang, Y.F.; Yu-Lee, L.Y. Multiple stat complexes interact at the interferon regulatory factor-1 interferon-gamma activation sequence in prolactin-stimulated Nb2 T cells. Mol. Cell. Endocrinol. 1996, 121, 19-28. [CrossRef] 
32. Pedraz-Cuesta, E.; Fredsted, J.; Jensen, H.H.; Bornebusch, A.; Nejsum, L.N.; Kragelund, B.B.; Pedersen, S.F. Prolactin Signaling Stimulates Invasion via $\mathrm{Na}(+) / \mathrm{H}(+)$ Exchanger NHE1 in T47D Human Breast Cancer Cells. Mol. Endocrinol. 2016, 30, 693-708. [CrossRef] [PubMed]

33. Haxholm, G.W.; Nikolajsen, L.F.; Olsen, J.G.; Fredsted, J.; Larsen, F.H.; Goffin, V.; Pedersen, S.F.; Brooks, A.J.; Waters, M.J.; Kragelund, B.B. Intrinsically disordered cytoplasmic domains of two cytokine receptors mediate conserved interactions with membranes. Biochem. J. 2015, 468, 495-506. [CrossRef] [PubMed]

34. Legorreta-Haquet, M.V.; Chávez-Rueda, K.; Chávez-Sánchez, L.; Cervera-Castillo, H.; Zenteno-Galindo, E.; Barile-Fabris, L.; Burgos-Vargas, R.; Álvarez-Hernández, E.; Blanco-Favela, F. Function of Treg Cells Decreased in Patients With Systemic Lupus Erythematosus Due To the Effect of Prolactin. Medicine 2016, 95, e2384. [CrossRef] [PubMed]

35. Neradugomma, N.K.; Subramaniam, D.; Tawfik, O.W.; Goffin, V.; Kumar, T.R.; Jensen, R.A.; Anant, S. Prolactin signaling enhances colon cancer stemness by modulating Notch signaling in a Jak2-STAT3/ERK manner. Carcinogenesis 2014, 35, 795-806. [CrossRef]

36. Xu, Q.; Briggs, J.; Park, S.; Niu, G.; Kortylewski, M.; Zhang, S.; Gritsko, T.; Turkson, J.; Kay, H.; Yu, H.; et al. Targeting Stat3 blocks both HIF-1 and VEGF expression induced by multiple oncogenic growth signaling pathways. Oncogene 2005, 24, 5552-5560. [CrossRef] [PubMed]

37. Liang, R.; Chen, X.; Chen, L.; Wan, F.; Chen, K.; Sun, Y.; Zhu, X. STAT3 signaling in ovarian cancer: A potential therapeutic target. J. Cancer 2020, 11, 837-848. [CrossRef]

38. Hillmer, E.J.; Zhang, H.; Li, H.S.; Watowich, S.S. STAT3 signaling in immunity. Cytokine Growth Factor Rev 2016, $31,1-15$. [CrossRef]

39. Diehl, S.A.; Schmidlin, H.; Nagasawa, M.; Van Haren, S.D.; Kwakkenbos, M.J.; Yasuda, E.; Beaumont, T.; Scheeren, F.A.; Spits, H. STAT3-mediated up-regulation of BLIMP1 Is coordinated with BCL6 down-regulation to control human plasma cell differentiation. J. Immunol. 2008, 180, 4805-4815. [CrossRef]

40. Guo, Y.; Nemeth, J.; O’Brien, C.; Susa, M.; Liu, X.; Zhang, Z.; Choy, E.; Mankin, H.; Hornicek, F.; Duan, Z. Effects of siltuximab on the IL-6-induced signaling pathway in ovarian cancer. Clin. Cancer Res. 2010, 16, 5759-5769. [CrossRef]

41. Ji, T.; Gong, D.; Han, Z.; Wei, X.; Yan, Y.; Ye, F.; Ding, W.; Wang, J.; Xia, X.; Gao, Q.; et al. Abrogation of constitutive Stat3 activity circumvents cisplatin resistant ovarian cancer. Cancer Lett. 2013, 341, 231-239. [CrossRef] [PubMed]

42. Diaz, N.; Minton, S.; Cox, C.; Bowman, T.; Gritsko, T.; Garcia, R.; Eweis, I.; Wloch, M.; Sullivan, D.; Muro-Cacho, C.A.; et al. Activation of stat 3 in primary tumors from high-risk breast cancer patients is associated with elevated levels of activated SRC and survivin expression. Clin. Cancer Res. 2006, 12, 20-28. [CrossRef] [PubMed]

43. Gritsko, T.; Williams, A.; Turkson, J.; Kaneko, S.; Bowman, T.; Huang, M.; Nam, S.; Eweis, I.; Diaz, N.; Jove, R.; et al. Persistent activation of stat 3 signaling induces survivin gene expression and confers resistance to apoptosis in human breast cancer cells. Clin. Cancer Res. 2006, 12, 11-19. [CrossRef] [PubMed]

44. Lu, L.; Zhu, F.; Zhang, M.; Li, Y.; Drennan, A.C.; Kimpara, S.; Rumball, I.; Selzer, C.; Cameron, H.; Kellicut, A.; et al. Gene regulation and suppression of type I interferon signaling by STAT3 in diffuse large B cell lymphoma. Proc. Natl. Acad. Sci. USA 2018, 115, E498-E505. [CrossRef] [PubMed]

45. Pathania, A.S.; Kumar, S.; Guru, S.K.; Bhushan, S.; Sharma, P.R.; Aithagani, S.K.; Singh, P.P.; Vishwakarma, R.A.; Kumar, A.; Malik, F. The synthetic tryptanthrin analogue suppresses STAT3 signaling and induces caspase dependent apoptosis via ERK up regulation in human leukemia HL-60 cells. PLoS ONE 2014, 9, e110411. [CrossRef]

46. Zhou, J.; Bi, C.; Janakakumara, J.V.; Liu, S.C.; Chng, W.J.; Tay, K.G.; Poon, L.F.; Xie, Z.; Albert, D.H.; Chen, C.S.; et al. Enhanced activation of STAT pathways and overexpression of survivin confer resistance to FLT3 inhibitors and could be therapeutic targets in AML. Blood 2009, 113, 4052-4062. [CrossRef]

47. Gharibi, T.; Babaloo, Z.; Hosseini, A.; Abdollahpour-Alitappeh, M.; Hashemi, V.; Marofi, F.; Nejati, K.; Baradaran, B. Targeting STAT3 in cancer and autoimmune diseases. Eur. J. Pharmacol. 2020, 878, 173107. [CrossRef]

48. Flanagan, S.E.; Haapaniemi, E.; Russell, M.A.; Caswell, R.; Allen, H.L.; De Franco, E.; McDonald, T.J.; Rajala, H.; Morgan, N.G.; Hattersley, A.T.; et al. Activating germline mutations in STAT3 cause early-onset multi-organ autoimmune disease. Nat. Genet. 2014, 46, 812-814. [CrossRef]

49. Haapaniemi, E.M.; Kaustio, M.; Rajala, H.L.; Van Adrichem, A.J.; Kainulainen, L.; Glumoff, V.; Doffinger, R.; Kuusanmäki, H.; Mustjoki, S.; Kere, J.; et al. Autoimmunity, hypogammaglobulinemia, lymphoproliferation, and mycobacterial disease in patients with activating mutations in STAT3. Blood 2015, 125, 639-648. [CrossRef]

50. De La Varga Martínez, R.; Rodríguez-Bayona, B.; Añez, G.A.; Medina Varo, F.; Pérez Venegas, J.J.; Brieva, J.A.; Rodríguez, C. Clinical relevance of circulating anti-ENA and anti-dsDNA secreting cells from SLE patients and their dependence on STAT-3 activation. Eur. J. Immunol. 2017, 47, 1211-1219. [CrossRef]

51. Edwards, L.J.; Mizui, M.; Kyttaris, V. Signal transducer and activator of transcription (STAT) 3 inhibition delays the onset of lupus nephritis in MRL/lpr mice. Clin. Immunol. 2015, 158, 221-230. [CrossRef] [PubMed]

52. Du, Y.; Zhang, W.; Liu, S.; Feng, X.; Gao, F.; Liu, Q. S3I-201 ameliorates tubulointerstitial lesion of the kidneys in MRL/lpr mice. Biochem. Biophys. Res. Commun. 2018, 503, 177-180. [CrossRef] [PubMed]

53. Wallace, D.J.; Furie, R.A.; Tanaka, Y.; Kalunian, K.C.; Mosca, M.; Petri, M.A.; Dörner, T.; DeLozier, A.M.; Janes, J.M.; Hoffman, R.W.; et al. Baricitinib for systemic lupus erythematosus: A double-blind, randomised, placebo-controlled, phase 2 trial. Lancet 2018, 392, 222-231. [CrossRef] 
54. Miletic, A.V.; Jellusova, J.; Cato, M.H.; Lee, C.R.; Baracho, G.V.; Conway, E.M.; Rickert, R.C. Essential Role for Survivin in the Proliferative Expansion of Progenitor and Mature B Cells. J. Immunol. 2016, 196, 2195-2204. [CrossRef] [PubMed]

55. Métais, J.Y.; Winkler, T.; Geyer, J.T.; Calado, R.T.; Aplan, P.D.; Eckhaus, M.A.; Dunbar, C.E. BCL2A1a over-expression in murine hematopoietic stem and progenitor cells decreases apoptosis and results in hematopoietic transformation. PLoS ONE 2012, 7, e48267. [CrossRef]

56. Adams, C.M.; Kim, A.S.; Mitra, R.; Choi, J.K.; Gong, J.Z.; Eischen, C.M. BCL-W has a fundamental role in B cell survival and lymphomagenesis. J. Clin. Investig. 2017, 127, 635-650. [CrossRef]

57. Pahlavan, Y.; Kahroba, H.; Samadi, N.; Karimi, A.; Ansarin, K.; Khabbazi, A. Survivin modulatory role in autoimmune and autoinflammatory diseases. J. Cell. Physiol. 2019, 234, 19440-19450. [CrossRef]

58. Gravina, G.; Wasén, C.; Garcia-Bonete, M.J.; Turkkila, M.; Erlandsson, M.C.; Töyrä Silfverswärd, S.; Brisslert, M.; Pullerits, R.; Andersson, K.M.; Bokarewa, M.I.; et al. Survivin in autoimmune diseases. Autoimmun. Rev. 2017, 16, 845-855. [CrossRef] 